\title{
MASTER c00-2245-70
}

COOLANT MIXING IN LMFBR ROD BUNDLES AND

OUTLET PLENUM MIXING TRANSIENTS

Progress Report

Principal Investigators

Neil E. Todreas - Tasks I and II

Michael W. Golay - Task III

Lothar Wolf - Task IV
Massachusetts Institute of Technology
Department of Nuclear Engineering
Cambridge, Massachusetts 02139

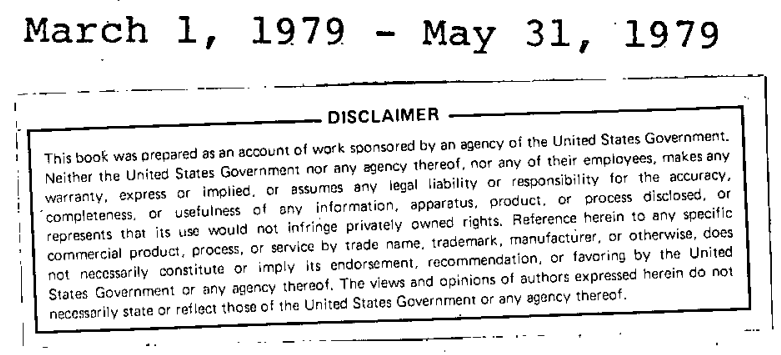

Prepared for the U.S. Department of Energy

under Contract No. EY-76-S-02-2245 


\section{DISCLAIMER}

This report was prepared as an account of work sponsored by an agency of the United States Government. Neither the United States Government nor any agency Thereof, nor any of their employees, makes any warranty, express or implied, or assumes any legal liability or responsibility for the accuracy, completeness, or usefulness of any information, apparatus, product, or process disclosed, or represents that its use would not infringe privately owned rights. Reference herein to any specific commercial product, process, or service by trade name, trademark, manufacturer, or otherwise does not necessarily constitute or imply its endorsement, recommendation, or favoring by the United States Government or any agency thereof. The views and opinions of authors expressed herein do not necessarily state or reflect those of the United States Government or any agency thereof. 


\section{DISCLAIMER}

Portions of this document may be illegible in electronic image products. Images are produced from the best available original document. 


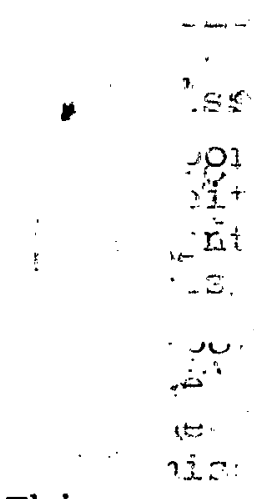

"This report was prepared as an account of Government-sponsored work. Neither the United States, or the Energy Research and Development Administration nor any person acting on behalf of the Commission
A. Makes any warranty or representation, expressed or implied, with respect to the accuracy, completeness or usefulness of the information contained in this report, or that the use of any information, apparatus method, or process disclosed in this report may not infringe privately owned rights; or
B. Assumes any liabilities with respect to the use of, or for damages resulting from the use of, any infor- mation, apparatus, method, or process disclosed in this report.
As used in the above, 'person acting on behalf of the commis- sion' includes any employee or contractor of the Administration or employee of such contractor, to the extent that such employee or contractor prepares, disseminates, or provides access to, any information pursuant to his employment or contract with the Administration or his employment with such contractor." 
Reports and Papers Published Under

MIT Coolant Mixing in LMFBR Rod Bundles Project

A. Quarterly Progress Reports

(Available from:

National Technical Information Service U.S. Department of Commerce

Springfield, VA 22151)

\begin{tabular}{|c|c|}
\hline & $\mathrm{dd} \mathrm{Ju}$ \\
\hline $0-2245-2$ & eriod December 1, 1972 - February 28, 1973 \\
\hline $0-2245-3$ & od March 1, 1973 - May 31, 1973 \\
\hline $0-2245-6$ & Period June 1, 1973 - August 31, 1973 \\
\hline $0-2245-7$ & od September 1, 1973 - November 30, 1973 \\
\hline $0-2245-8$ & exiod December 1, 1973 - February 28, 1974 \\
\hline $0-2245-10$ & 1, 1974 - May 31, 1974 \\
\hline $0-2245-13$ & I, 1974 - August 31, 1974 \\
\hline $0-2245-14$ & eriod September 1, 1974 - November 30, 1974 \\
\hline $0-2245-15$ & eriod December 1, 1974 - February 28, 1975 \\
\hline $45-23$ & od March 1, 1975 - May 31, 1975 \\
\hline $00-2245-25$ & Period June 1, 1975 - August 31, 1975 \\
\hline $0-2245-26$ & Period September 1, 1975 - November 30, 1975 \\
\hline $0-2$ & od December 1, 1975 - February 29, 1976 \\
\hline $00-2245-30$ & Period March 1, 1976 - May 31, 1976 \\
\hline $0-2245-31$ & Period June 1, 1976 - August 31, 1976 \\
\hline $50-22$ & eriod September 1, 1976 - November 30, 1976 \\
\hline $0-2245-38$ & Period December 1, 1976 - February 28, 1977 \\
\hline $0-2245-50$ & Period March 1, 1977 - May 31, 1977 \\
\hline $0-2245-53$ & Period June 1, 1977 - August 31, 1977 \\
\hline $0-2245-60$ & Period September 1, 1977 - November 30, 1977 \\
\hline $00-2245-63$ & Period pecember 1, 1977 - February 28, 1978 \\
\hline $00-2245-64$ & Period March 1, 1978 - May 31, 1978 \\
\hline $0-2245-65$ & 1,1978 - August 31,1978 \\
\hline $0-2245-66$ & er 1,1978 - November 30,1978 \\
\hline $0-2245-69$ & eer 1, 1978 - February 28, 1979 \\
\hline & 1979 - May 31, \\
\hline
\end{tabular}


Reports Issued Under This Contract

$-1$

B. Topical Reports (Available from National Technical

出 Information Service, U.S. Depart-

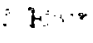

$\therefore$

em ment of Commerce, Springfield, VA 22151)

E. Khan and N. Todreas, "A Review of Recent Analytical and Txperimental Studies Applicable to LMFBR Fuel and Blanket Assembly Design", COO-2245-4TR, MIT, September 1973.

E. Khan, W. Rohsenow, A. Sonin and N. Todreas, "A Simplified Approach for Predicting Temperature Distribution in Wire Wrapped Assemblies", COO-2245-5TR, MIT, September 1973.

T. Eaton and N. Todreas, "Instrumentation Methods for Interchannel Coolant Mixing Studies in Wire-Wrap Spaced Nuclear Fuel Assemblies", COO-2245-9TR, MIT, June 1974.

Y. B. Chen, K. Ip, N. E. Todreas, "Velocity Measurements in Edge Subchannels of Wire Wrapped LMFBR Fuel Assemblies", COO-2245-11TR, MIT, September 1974.

E. Khan, N. Todreas, N. Rohsenow, A. A. Sonin, "Analysis of Mixing Data Relevant to Wire-TVrapped Fuel Assembly Thermal-Hydraulic Design", COO-2245-12TR, IIT, September 1974 .

E. Khan, W. Rohsenow, A. Sonin, N. Todreas, "A Porous Body Model for Predicting Temperature Distributions in Wire Wrapped Fuel and Blanket Assemblies of an LMFBR", COO-2245-16TR, MIT, June 1975.

* E. Khan, W. M. Rohsenow, A. Sonin, N. Todreas, "Input Parameters to the ENERGY Code (To be used with the ENERGY Codes Manual), COO-2245-17TR, MIT, May 1975.

E. Khan, W. Rohsenow, A. Sonin, N. Todreas, "Manual for ENERGY Codes I, II, III", COO-2245-18TR, MIT, May 1975.

E. Khan, W. Rohsenow, A. Sonin, N. Todreas, "Manual for ENERGY Codes I, II, III Computer Programs", COO-2245-18TR, Revision I, MIT, July 1976:

P. Carajilescov and N. Todreas, "Experimental and Analytical Study of Axial Turbulent Flows in an Interion subchannel of a Bare Rod Bundle", COO-2245-19TR, MIT.

B. Chen and N. Todreas, "Prediction of Coolant Temperature Field in a Breeder Reactor Including Interassembly Heat Transfer", COO-2245-20TR, MIT, May 1975. 


\section{B. Topical Reports (Continued)}

B. Chen and N. Tódreas, "Prediction of Coolant Temperature Field in a Breeder Reactor Including Interassembly Heat Transfer", COO-2245-20TR, Revision I, MIT, December 1976 .

F. Carre and N. Todreas, "Development of Input Data to ENERGY Code for Analysis of Reactor Fuel Bundles", COO-2245-2ITR, MIT, May 1975.

H. Ninokata and N. E. Todreas, "Turbulent Momentum Exchange Coefficients for Reactor Fuel Bundle Analysis", COO-2245-22TR, MIT, June 1975.

R. Anoba and $\mathrm{N}$. Todreas, "Coolant Mixing in LMFBR Rod Buncles and outlet Plenum Mixing Transients, Coo-2245-24TR, MIT, August 1975.

* B. Bosy, "Fabrication Details for Wire Wrapped Fuel Assembly Components", COO-2245-27TR, MIT, November 1975.

Ralph G. Bennett and Michael W. Golay, "Interferometric Investigation of Turbulently Fluctuating Temperature in an LMFBR Outlet Plenum Geometry", COO-2245-29TR, MIT, June 1976.

N. E. Todreas, "Thermal Analysis Methods for LMFBR Wire Wrapped Bundles", COO-2245-32TP, MIT, November 1976.

K. L. Basehore and N. E. Todreas, "Development of Stability Criteria and an Interassembly Conduction Model for the Thermal-Hydraulics Code SUPERENERGY", COO-2245-33TR, MIT, December 1976.

Robert Masterson and ijeil E. Todreas, "Analysis of the Feasibility of Implementing an Implicit Temporal Differencing scheme in the SUPERENERGY Code", COO-2245-35TR, MIT, February 1977.

S. Glazer, C. Chiu and N. Todreas, "Collection and Evaluation of Salt Mixing Data with the Real Time Data Acquisition System", COO-2245-36TR, MIT, April 1977.

B. Mikic, E. U. Khan and N. E. Todreás, "An Approximate Method for Predicting Temperature Distribution in Wire Wrapped Fuel Assemblies of an LMFBR", COO-2245-37TR, MIT, April 1977.

C. Chiu and N. Todreas, "Development of a Technique for Subchannel Flow Rate Measurements in LMFBR Wire Wrapped. Assemblies", COO-2245-39TR, July 1977. 
B. Topical, Reports (Continued)

C. Chiư and N. Todreas, "WARD Blanket Assembly Pre-Test

Predicțö́s by SUPERENERGY", COO-2245-40TR, MIT, MaY 1977.

C. Chitu No Todreas, W. M. Rohsenow, "Flow Split Mea-

surements in LMFBR Blanket Assemblies", COO-2245-4lTR, MIT, Ap̈rit 1978.

C. Chivy Hawley, W. M. Rohsenow and N. Todreas, "Pressure Drop Measurements in Wire Vrapped Blanket Assemblites", COO-2245-42TR, July 1977.

C. Chiư, ir. M. Rohsenow and N. Todreas, "Mising Experiments in LMFBR Wire Wrapped Blänket Assemblies", COO-2245-43TR, April 1978.

Yi Ben Chen and Michael W. Golay, "Coolant Mixing in the LMFBR Outlet Plenum", COO-2245-44TR, June 1977 .

$\mathrm{J}$. Kelly and $\mathrm{N}$. Todreas, "Turbulent Interchange in Triangular Array Bare Rod Bundles", CoO-2245-45TR, July 1977.

K. L. Basehore and N. E. Todreas, "Assessment of the Need to Incorporate a Variable Swirl Flow Model into the ENERGY Code", COO-2245-46TR, July 1977.

K. L. Basehore and $N$. Todreas, "Analysis of the ThermalHydraulic Behavior in the CPBR Secondary Control Assembly, Including Interassembly Heat Transfer Effects", COO-2245-47TR, July 1977.

J. G. Bartzis and N. E. Todreas, "Hydrodynamic Behavior of a Bare Rod Bundle", COO-2245-48TR, MIT, June 1977.

M. R. Fakori-Monazah and N. E. Todreas, "Measurement and Analysis of Flow wall Shear stress in an Interior Subchannel of Triangular Array Rods", COO-2245-49TR, MIT, August 1977.

A. S. Hanson and N. E. Todreas, "Fluid Mixing Studies in an Hexagonal 6l-Pin, Wire-wrapped Rod Bundle", Coo-2245-5ITR, MIT, August 1977.

S. Glaser, N. Todreas, W. Rohsenow, and A. Sonin, "TRANSENERGY S,M - Computer Codes for Coolant Temperature Prediction in LMFBR Cores During Transient Events", To be issued as COO-2245-52TR, MIT.

C. Chiu, W. M. Rohsenow, and N. E. Todreas, "Mixing Experiments in an Alternating Wire wrapped Assembly", COO-2245-54TR, MIT, December 1977. 
B. Topical Reports (Continued)

* C. Chiu, W. M. Rohsenow and N. E. Todreas, "Turbulent Sweeping Flow Mixing Model for Wire Wrapped LMFBR Assemblies", COO-2245-55TR, MIT, April 1978.

C. Chiu, W. M. Rohsenow and N. E. Todreas, "Flow split Model for LMFBR Wire Wrapped Assemblies", COO-2245-56TR, MIT, April 1978.

K. Basehore and N. E. Todreas, "SUPERENERGY: Multiassembly Thermal-Hydraulic LMFBR Code", To be issued as Topical Report COO-2245-57TR, Department of Nuclear Engineering, MIT.

$\mathrm{C}-\mathrm{N}$. Wong and L. Wolf, "A 3-D Slug Flow Heat Transfer Analysis of Coupled Coolant Cells in Finite IMFBR Bundles", COO-2245-58TR, MIT, February 1978.

Roohollah Karimi and L. Wolf, "Two Dimensional Structural Analysis of Reactor Fuel Element Claddings Due to Local Effects", COO-2245-59TR, MIT, April 1978.

Vincent Manno and Michael Golay, "Measurement of Heat and Momentum Eddy Diffusivities in Recirculating LMFBR outlet Plenum Flows", COO-2245-6ITR, MIT, June 1978.

Hafeez Khan, Chong Chiu and Neil Todreas, "Laboratory Manual for Salt Mixing Test in Rod Bundles", COO-2245-62TR, MIT, October 1978.

Revisions Issued

S. F. Wang and N. E. Todreas, "Input Parameters to Codes Which Analyze LMFBR Wire-Wrapped Bundles," COO-2245-17TR (Revision I), MIT, May 1979, (Supercedes COO-2245-17TR).

King-Wo Chiu, "Fabrication Details for Wire-Wrapped Fuel Assembly Components,". COO-22.45-27TR (Revision II), MIT, September 1979, (Supercedes COO-2245-27TR).

C. Chiu, W. M. Rohsenow, and N. E. Todreas, "Turbulent Sweeping Flow Mixing Model for Wire-Wrapped LMFBR Assemblies," COO-2245-55TR (Revision I), MIT, October 1978, (Supercedes COO-2245-55TR) . 


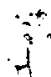

Papers and Summaries

Y. B. Chen, K. I. Ip, and N. E. Todreas, "Velocity Measurements in Edge Channels of Wire-Wrapped LMFBR Fuel Assemblies,". American Nuclear Society Transactions, Vol. 19, 1974,

pp. $323 \div 324$. in

P. Carajilescov and N. Todreas, "Experimental and Analytical Study of Axial Turbulent Flows in an Interior subchannel of a Bare Rod Bundle," J. of Heat Transfer, Vol. 98, No. 2, May $1976 \%$ pp. 262-268, (Included as Appendix to Quarterly Progress Report, COO-2245-15).

E. Khan, W. Rohsenow, A. Sonin, and N. Todreas, "A Porous Body Model for Predicting Temperature Distribution in WireWrapped Fuel Rod Assemblies," Nuclear Engineering and Design, 35 (1975), pp. 1-12.

E. Khan, W. Rohsenow, A. Sonin, and N. Todreas, "A Porous Body Model for Predicting Temperature Distribution in WireWrapped Rod Assemblies operating in Combined Forced and Free Convection," Nuclear Engineering and Design, 35 (1975), pp. 199-211.

R. G. Bennett and M. W. Golay, "Development of An Optical Method for Measurement of Temperature Fluctuation in Turbulent Flows," American Nuclear Society Transactions, Vol. 22, 1975, p. 581.

B. Chen and N. Todreas, "Prediction of the Coolant Temperature Field in a Breeder Reactor Including Interassembly Heat Transfer," Nuclear Engineering and Design, 35, (1975), pp. 423-440, (Included as Appendix to Quarterly Progress Report, COO-2245-23).

R. Bennett and M. W. Golay, "Interferometric Investigation of Turbulently Fluctuating Temperature in an LMFBR outlet Plenum Geometry," Presented at the ASME Annual Winter Meeting, December, 1976, (Included as Appendix in Quarterly Progress Report, CoO-2245-30).

B. B. Mikic, E. U. Khan, and N. E. Todreas, "An Approximate Method for Predicting Temperature Distribution in WireWrapped Fuel Assemblies of a Liquid Metal Fast Breeder Reactor," Mech. Res. Comm., Vol. 3, (1976), pp. 353-360.

I. Wolf, R. Karimi, J. Y. Kim, C. N. Wong, and M. K. Yeung, "2-D Thermoelastic Analysis of LMFBR Fuel Rod Claddings," Paper C4/d, 4th International Conf. Structural Mechanics in Reactor Technology, San Francisco, August 1977. 


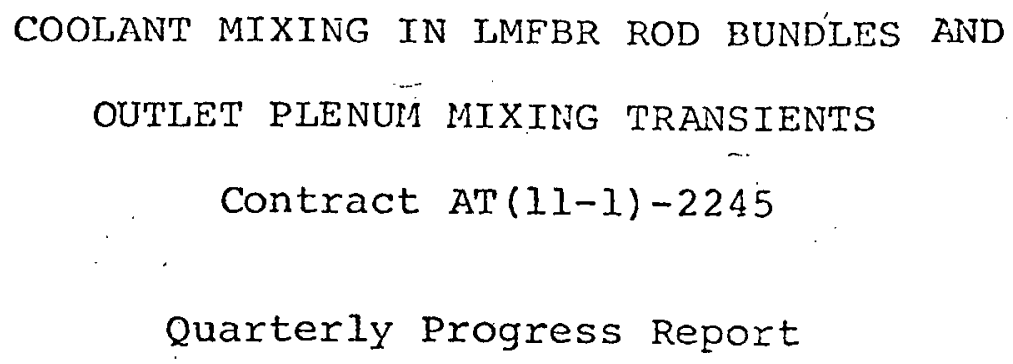

The work of this contract has been divided into the following Tasks:

TASK I: BUNDLE GEOMETRY (WRAPPED AND BARE RODS)

TASK IA: Assessment of Available Data

TASK IB: Experimental Bundle Vater Mixing Investigation

TASK IC: Experimental Bundle Peripheral

Velocity Measurements

(Laser Anemometer)

TASK ID: Analytic Model Development - Bundles

TASK II: SUBCHANNEL GEOMETRY (BARE RODS)

TASK IIA: Assessment of Available Data

TASK IIB: Experimental Subchannel water

Mixing Investigation

TASK IIC: Experimental Subchannel Local

parameter Measurements

(Laser Anemometer)

TASK IID: Analytic Model Development - Subchannels

TASK III: LMFBR OUTLET PLENUM FLOW MIXING

TASK IIIA: Analytical and Experimental Investigation of Velocity and Temperature Fields

TASK IV: THEORETICAL DETERMINATION OF LOCAL TEMPERATURE FIELDS IN LMFBR FUEL ROD BUNDLES 
TASK I: BUNDLE GEOMETRY (WRAPPED AND BARE RODS)

I.A. Assessment of Available Data

( Jim Hawley)

Compilation of bundle average friction factor data for various geometries has been completed. Models for laminar and turbulent flow, subchannel pressure drop were developed in conjunction with Dr. C. Chiu of Combustion Engineering, and from these models, expressions for laminar and turbulent flow subchannel friction factors and flow split parameters were obtained. These results were used to obtain expressions for laminar and turbulent flow bunde friction factors. The calibration constants in these latter expressions were then calibrated by comparison of predictions with data. The transition region values for subchannel and bundle friction factors were obtained by superposing the respective laminar and turbulent values in the following manner :

$$
f_{i}=\left[\left(f_{i L}\right)^{\ell}+\left(f_{i T}\right)^{\ell}\right] 1 / \ell
$$

where $i=1,2$, or $b$. It is assumed that the constant $l$ has the same value for $i=1,2$, or $b$, so, the constant $\ell$ is calibrated by comparing $f_{b}$ with the data.

The expressions for $f_{i L^{\prime}} f_{i T^{\prime}} f_{b L^{\prime}}$ and $f_{b T}$ are:

$$
f_{i L}=\frac{C^{\prime}}{R_{i}}+C_{\beta i}\left(\frac{\operatorname{Ar} i}{\operatorname{As} i}\right)\left(\frac{D e i}{H}\right)\left(1-\frac{D_{w}}{2 D e_{i}}\right) \frac{C_{\psi}}{R_{i}} \quad, i=1,2
$$




$$
\begin{aligned}
& \text { A } \\
& \sqrt{\overline{P_{5}^{*}}} \\
& \mathrm{f}_{1 \mathrm{~T}}=\left[1+2200\left(\frac{\mathrm{A}_{\mathrm{rI}}}{\mathrm{A}_{\mathrm{SI}}}\right)\left(\frac{D \mathrm{De}_{I}}{\mathrm{H}}\right)\left(\frac{\mathrm{P}^{2}}{\pi^{2} \mathrm{p}^{2}+\mathrm{H}^{2}}\right)\right]\left\{1+\mathrm{C}_{\mathrm{C}}^{2}\left(\frac{D e_{1}}{\mathrm{H}}\right)\left(\frac{\mathrm{P}^{2}}{\pi^{2} \mathrm{P}^{2}+\mathrm{H}^{2}}\right)\right\} \frac{\mathrm{C}_{\mathrm{T}}}{\mathrm{Re}_{1}^{15}} \\
& \mathrm{f}_{2 \mathrm{~T}}=\left\{I+\left[1.9 \mathrm{n}_{\mathrm{A}} \frac{\mathrm{V}_{\mathrm{t}}}{\mathrm{V}_{\mathrm{A}}} \mathrm{gap}\right]^{2}\right\}^{1.375}\left\{1+\mathrm{C}_{\mathrm{C}}^{2}\left(\frac{\mathrm{De}}{\mathrm{H}}\right)\left(\frac{\mathrm{P}^{2}}{\pi^{2} \mathrm{P}^{2}+\mathrm{H}^{2}}\right)\right\} \frac{\mathrm{C}_{\mathrm{T}}}{\mathrm{Re}_{2}^{115}} \\
& \text { n } \\
& f_{b L}=f_{i L} \frac{D e_{b}}{D e_{i}} x_{i L}{ }^{2} \\
& f_{b T}=f_{i T} \frac{D e}{D e} x_{i T}^{2}
\end{aligned}
$$

where $C_{i}^{\prime}=-336(\mathrm{P} / \mathrm{D}-1)^{2}+340(\mathrm{P} / \mathrm{D}-1)+40 ; \mathrm{C}_{2}^{\prime}=-318.2(\mathrm{P} / \mathrm{D}-1)^{2}+290.9(\mathrm{P} / \mathrm{D}-1)+34.7$ $C_{T}=.115 ; C_{1}^{2}=650$ and $C_{\gamma}$ and the $C_{\beta i}$ still have to be calibrated. The expressions for $x_{i L}$ and $x_{i T}$ can be derived from the equal pressure drop assumption and continuity, but the expressions for $x_{i T}$ are the same as those derived in an earlier report by chiu. Also, the transition region values of the flow split parameters may be found from:

$$
x_{i}=\left(\begin{array}{ll}
f_{b} & D e_{i} \\
f_{i} & \frac{D e_{b}}{l}
\end{array}\right)^{1 / 2} \quad, i=1,2
$$

The details of the models developed may be found in the paper "Subchannel and Bundle Friction Factors and Flow split Parameters for Laminar, Transition and Turbulent Flow in wireWrapped Nuclear Fuel subassemblies," which will be published in the near future. 
IB. 1 61-Pin Fuel Bundle

(Paul Symolon)

During this quarter, data reduction of the mixing results for the 61-pin fuel bundle with 12 -inch lead length was completed. In Figure $1, \varepsilon_{1}^{*}$ is plotted against Reynolds number. As for the 6-inch lead results presented in the previous Quarterly Report, we find a dependence of $\varepsilon_{1}^{*}$ on injection depth. For both the 6-inch and 12-inch leads, we get better results for deeper injection. This dependence is expected to be a result of some problem in either the data reduction process or the salt injection process. This will be investigated in the next quarter. Figure 2 shows a plot of $\mathrm{C}_{1}$ vs. Reynolds number for an injection depth of 24 inches. Since only one injection depth was used, we found a single value for $C_{1}$, but other results have indicated that $C_{1}$ depends upon injection depth.

Table I shows the calibrated values of $C_{1}$ for the 61-pin bundle. $c_{1}$ is seen to vary with both injection depth and lead length. The variation with lead length is expected, since the swirl flow will tend to follow the wire-wrap in the edge subchannel. The variation with injection depth is believed to be a fictitious variation brought about by the salt injection process.

In the MIT salt injection tests, the salt solution is injected into the flow at an angle of $30^{\circ}$ from the vertical. The injection flow rate is such that the axial component of the injection velocity is equal to the axial component of the main bundle flow. This is done to minimize the disturbance produced by the injection. As shown by the velocity vector diagrams of Figure 3 , injection into an edge subchannel leads to a component of the injection 
velocity in the $\theta$ direction which exceeds the swirl velocity, $\mathrm{V}_{\theta}$ by $\Delta \mathrm{v}_{\theta}$ which is given by:

$$
\therefore \quad \Delta v_{\theta}=v_{m a}\left(\tan \theta-c_{1}\right)
$$

The effect of this $\Delta \mathrm{V}_{\theta}$ is to increase the experimentally measured values for $c_{1}$ by giving the salt an initial displacement downstream, as exhibited in Figure 4. For $c_{1}=.20$ with $\theta=30^{\circ}$, we have $\Delta \mathrm{V}_{\theta}=.38 \mathrm{~V}_{\mathrm{ma}}$. We would expect the measured $\mathrm{C}_{1}$ values to increase with $\Delta \mathrm{V}_{\cdot \theta} \cdot \Delta \mathrm{V}_{\theta}$ gets large as $\mathrm{C}_{1}$ gets small, or as the H/D ratio gets large, so as H/D gets larger the discrepancy between theory and experiment gets larger. ALso, we expect the streaming of salt to have a larger effect on $C_{1}$ for shallow injection depths. This is because the displacement of salt due to streaming is not negligible in comparison to the displacement of salt due to the actual swirl velocity.

Since a large amount of salt injection data is available for $P / D=1.25$ (see Table $I$ ), we can investigate this effect. Due to the streaming of salt, we expect the measured value of $c_{1}$ to exceed the correlation by an amount which increases with $H / D$ and decreases with injection depth. In Figure 5 the solid line shows the correlation, and the dotted line the expected trend. The data of Table I is included, and gives support to this hypothesis. In the next quarter, mixing experiments will be performed on the 217pin bundle to confirm these results and to show that saturation occurs for deep injections.

Work has also been done on the flow split relation of Reference 2. We know that the subchannel pressure drop depends 
on the subchannel velocity (V) and the subchannel geometry (G), so that:

$$
\begin{array}{ll}
\Delta \mathrm{P}_{1}=\mathrm{f}\left(\mathrm{V}_{1}, \mathrm{G}_{1}\right) & \mathrm{G}_{1} \equiv \text { Geometry of Subchannel } 1 \\
\Delta \mathrm{P}_{2}=\mathrm{f}\left(\mathrm{V}_{2}, \mathrm{G}_{2}\right) & \mathrm{G}_{2} \equiv \text { Geometry of Subchannel } 2
\end{array}
$$

Equating the subchannel pressure drops

$$
\Delta \mathrm{P}_{I}=\Delta \mathrm{P}_{2}
$$

We can solve explicitiy for the velocity ratio

$$
\frac{V_{2}}{V_{1}}=\frac{X_{2}}{X_{1}}=G
$$

Where $G$ is a function of the geometry of both subchannels.

This proves that the ratio $\frac{x_{2}}{x_{1}}$ is always independent of bundle size, $N$. A bundle continuity equation yields:

$$
\mathrm{N}_{1} \mathrm{~V}_{1} \mathrm{~A}_{1}+\mathrm{N}_{2} \mathrm{~V}_{2} \mathrm{~A}_{2}+\mathrm{N}_{3} \mathrm{~V}_{3} \mathrm{~A}_{3}=\mathrm{V}_{\mathrm{b}}\left(\mathrm{N}_{1} \mathrm{~A}_{1}+\mathrm{N}_{2} \mathrm{~A}_{2}+\mathrm{N}_{3} \mathrm{~A}_{3}\right)
$$

or, dividing by $\mathrm{V}_{\mathrm{b}}$ :

$$
\mathrm{X}_{1} \mathrm{~N}_{1} \mathrm{~A}_{1}+\mathrm{X}_{2} \mathrm{~N}_{2} \mathrm{~A}_{2}+\mathrm{x}_{3} \mathrm{~N}_{3} \mathrm{~A}_{3}=\mathrm{N}_{1} \mathrm{~A}_{1}+\mathrm{N}_{2} \mathrm{~A}_{2}+\mathrm{N}_{3} \mathrm{~A}_{3}
$$

dividing by $\dot{\mathrm{N}}_{1} \mathrm{~A}_{1}$ gives

$$
x_{1}+x_{2} \frac{N_{2} A_{2}}{N_{1} A_{1}}+x_{3} \frac{N_{3} A_{3}}{N_{1} A_{1}}=\frac{N_{2} A_{2}}{N_{1} A_{1}}+\frac{N_{3} A_{3}}{N_{1} A_{1}}
$$


If we assume ${ }^{\prime} x_{3}{ }^{\prime}=x_{2}$, we get:

$$
\therefore \quad x_{1}+x_{2} s=1+s
$$

where $S=\frac{N_{2} A_{2}}{N_{1} A_{1}}+\frac{N_{3} A_{3}}{N_{1} A_{1}}=\frac{A_{2}}{A_{1} N_{R}}+\frac{A_{3}}{A_{1} N_{R}^{2}} \quad N_{R}=\#$ of Rings of Pins Combining this result with $\frac{\mathrm{x}_{2}}{\mathrm{x}_{1}}=G$, we can solve for the flow splits:

$$
x_{1}=\frac{1+S}{1+S G} \quad x_{2}=\frac{1+S}{1 / G+S}
$$

Figure 6 shows a plot of $S$ vs. $N_{R}$. We can see that the plots for several different geometries almost coincide, indicating that $S$ depends on bundle size alone, and not upon the subchannel geometries. This is because the ratios $A_{2} / A_{1}$ and $A_{3} / A_{1}$ are nearly constant for different geometries.

For the turbulent flow split prediction of chiu et al [2], we have:

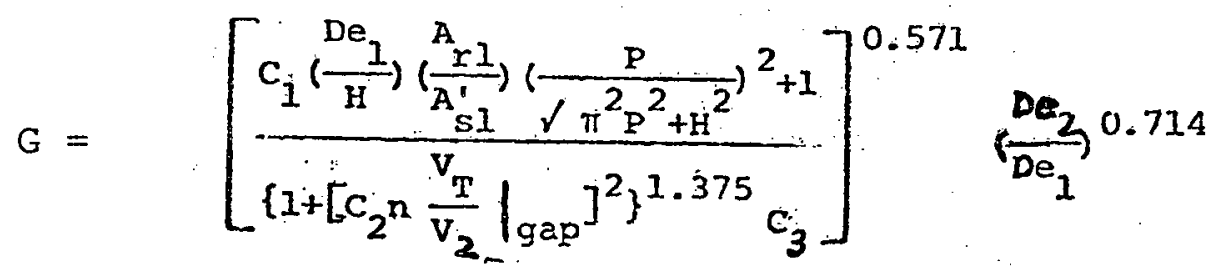

The constants $\mathrm{C}_{1}, \mathrm{C}_{2}$, and $\mathrm{C}_{3}$ were determined from a least squares fit of the data to be:

$$
\begin{aligned}
& c_{1}=2200.0 \\
& c_{2}=1.9 \\
& c_{3}=1.2
\end{aligned}
$$


With this, we can plot $G$ vs. $P / D$ and $H / D$ as shown in Figure 7 . This plot, along with Figure 6 allows: us to calculate the flow splits for bundles of various sizes (S) and geometries (G). The results of such a calculation are shown in Figure 8 .

In the next quarter, work will continue on the 217 -pin bundle. Flowsplit measurements were started, but the flow collectors were found to be slightly large. While new ones are being made, pressure drop data will be taken. Flow split and mixing will follow.

\section{REFERENCES}

1. Hanson, A. S., and Todreas, N. E., "Fluid Mixing Studies in a Hexagonal 61-Pin, Wire-Wrapped Rod Bundle," Co0-2245-51TR, August 1977 , MIT.

2. Chiu, C., Rohsenow, W. M., and Todreas, N. E., "Flow Split Model for LMFBR Wire-Wrapped Assemblies," To be published as COO-2245-56TR, Revision I, MIT. 


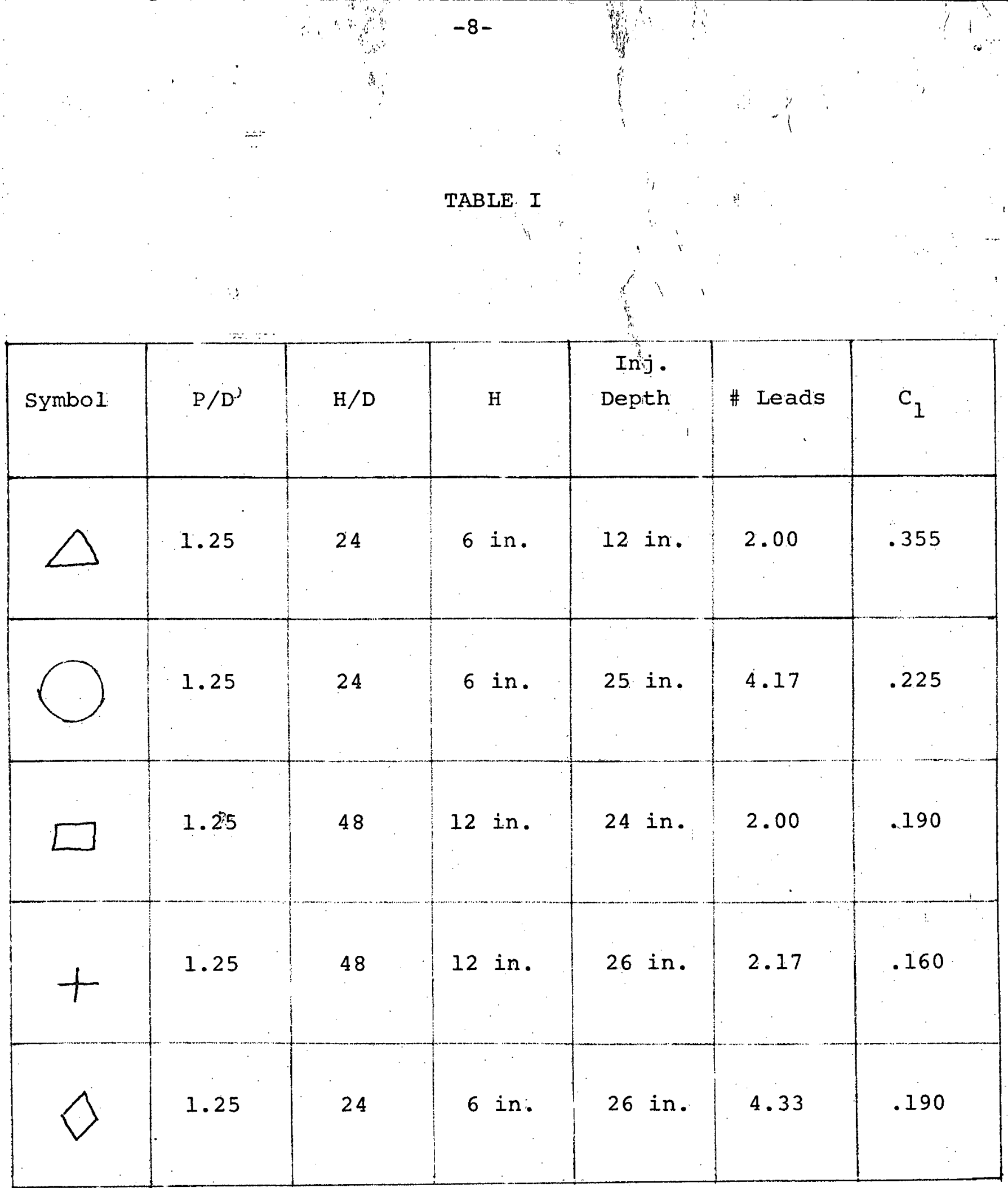

* Indicates data point from Reference I: 


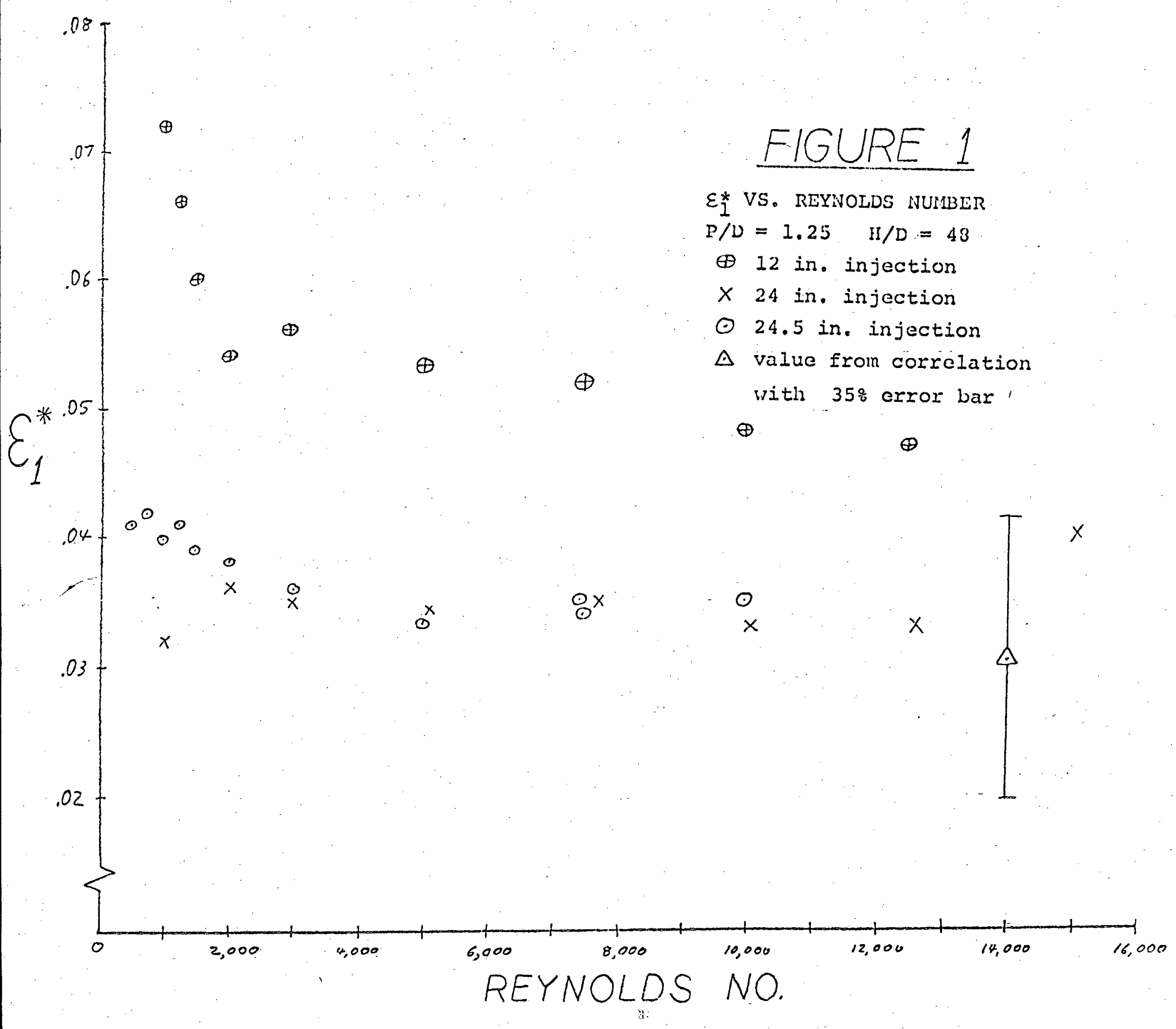




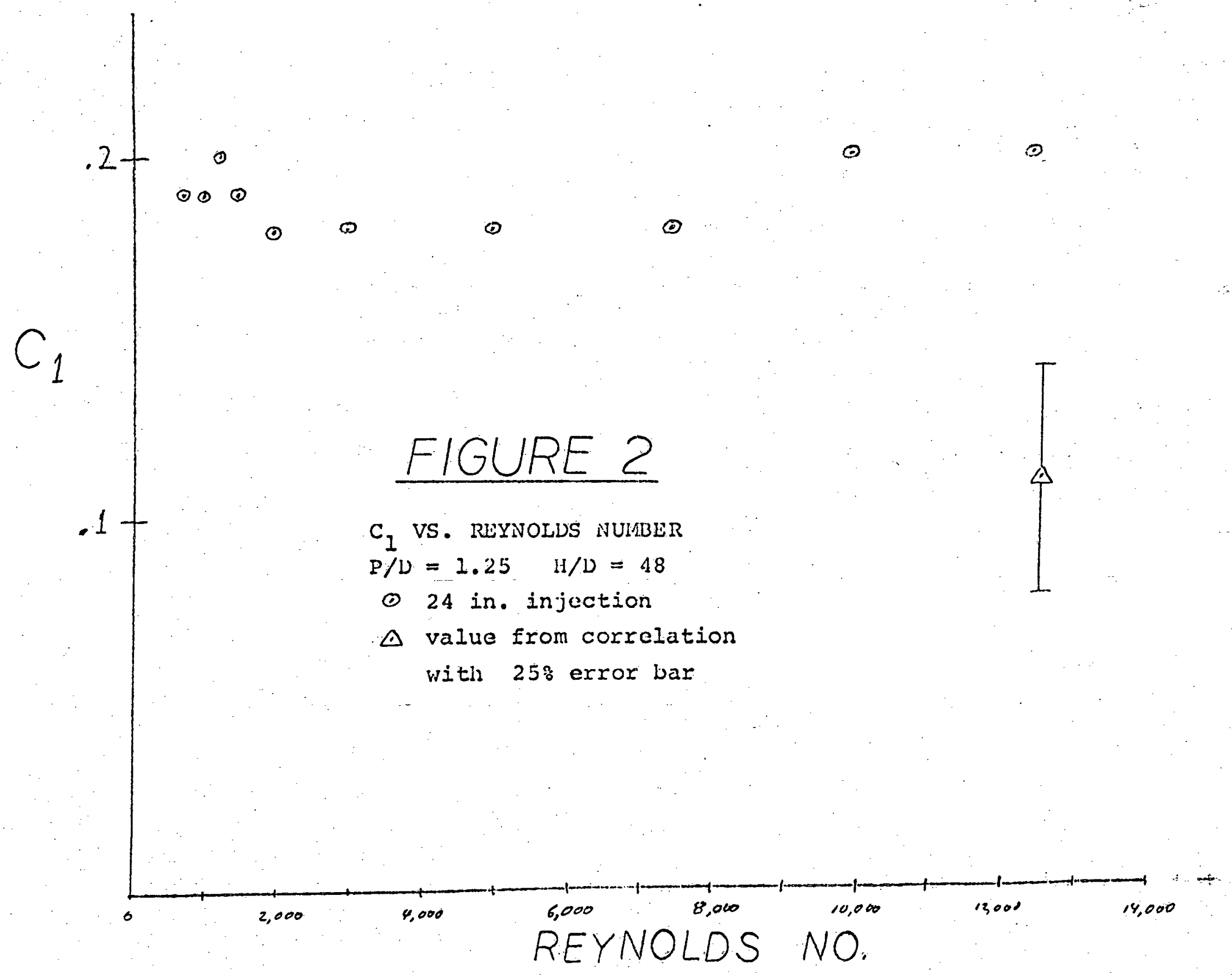


FIGURE 3

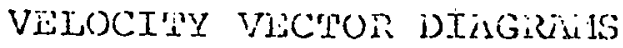

Susiserisitu:

$$
\begin{aligned}
& \because-\text { - an: Econ }
\end{aligned}
$$

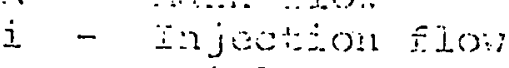

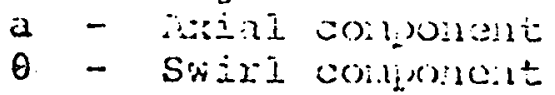

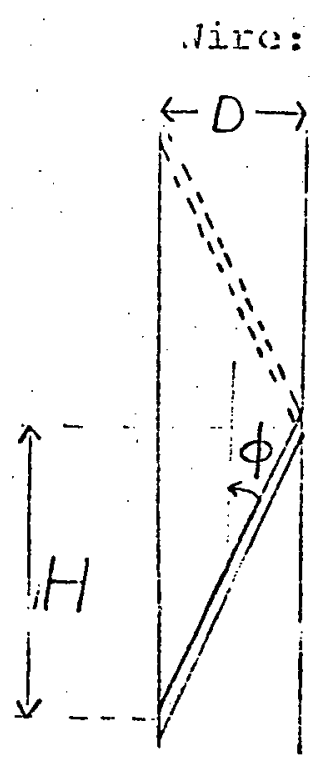

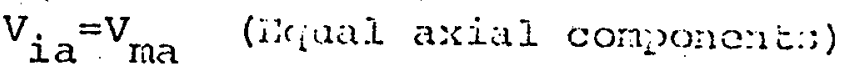

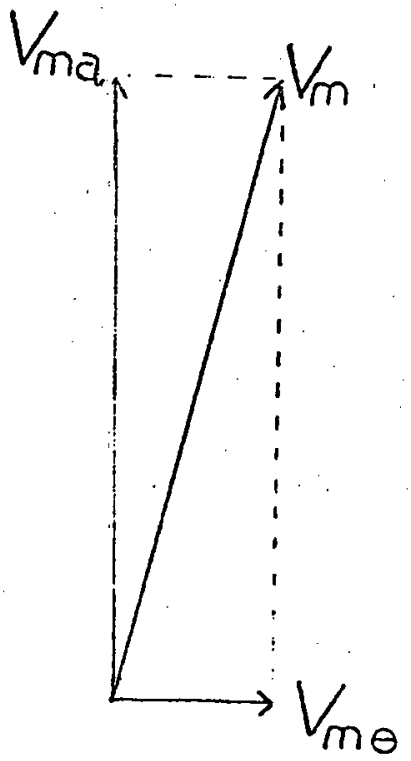

Inspection slow and natal flor:

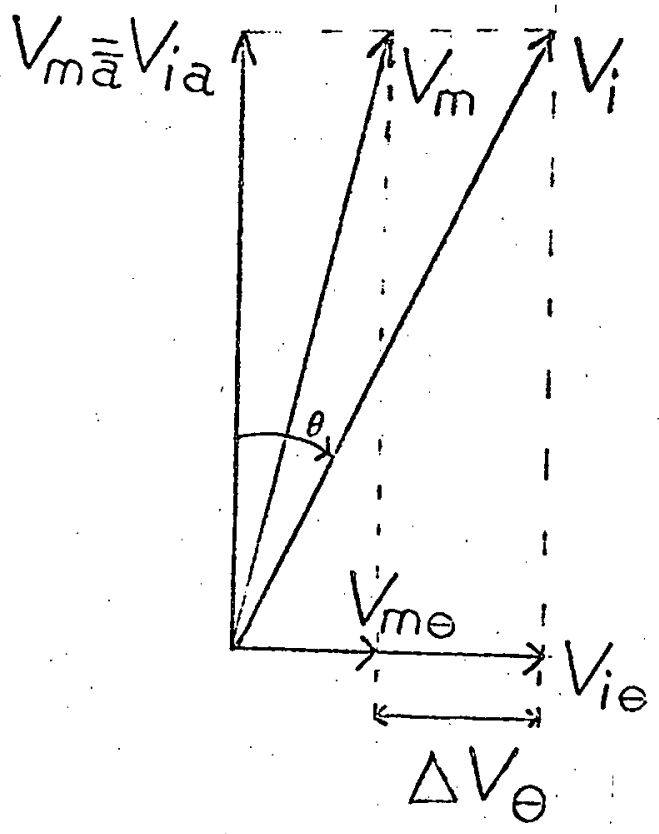

$$
\begin{aligned}
& v_{m \theta}=v_{m a} c_{1} \\
& v_{i \theta}=v_{i a} \tan \theta=v_{m a} \tan \theta \\
& \Delta v_{\theta}=v_{i \theta}-v_{m \theta}=v_{m a}\left(\tan \theta-c_{1}\right)
\end{aligned}
$$$$
\text { FIGURE } 4
$$

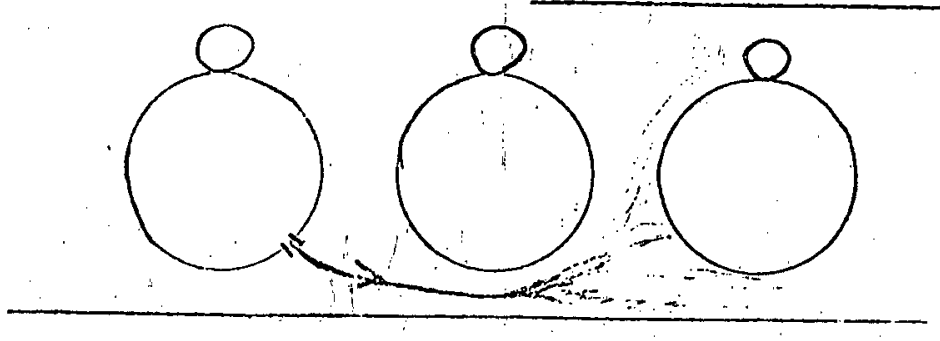

Defect of $\Delta v_{\theta}$ is to increase tile calibrated value for $\mathbf{c}_{1}$ by giving tile salt an initial displacement downstream. 


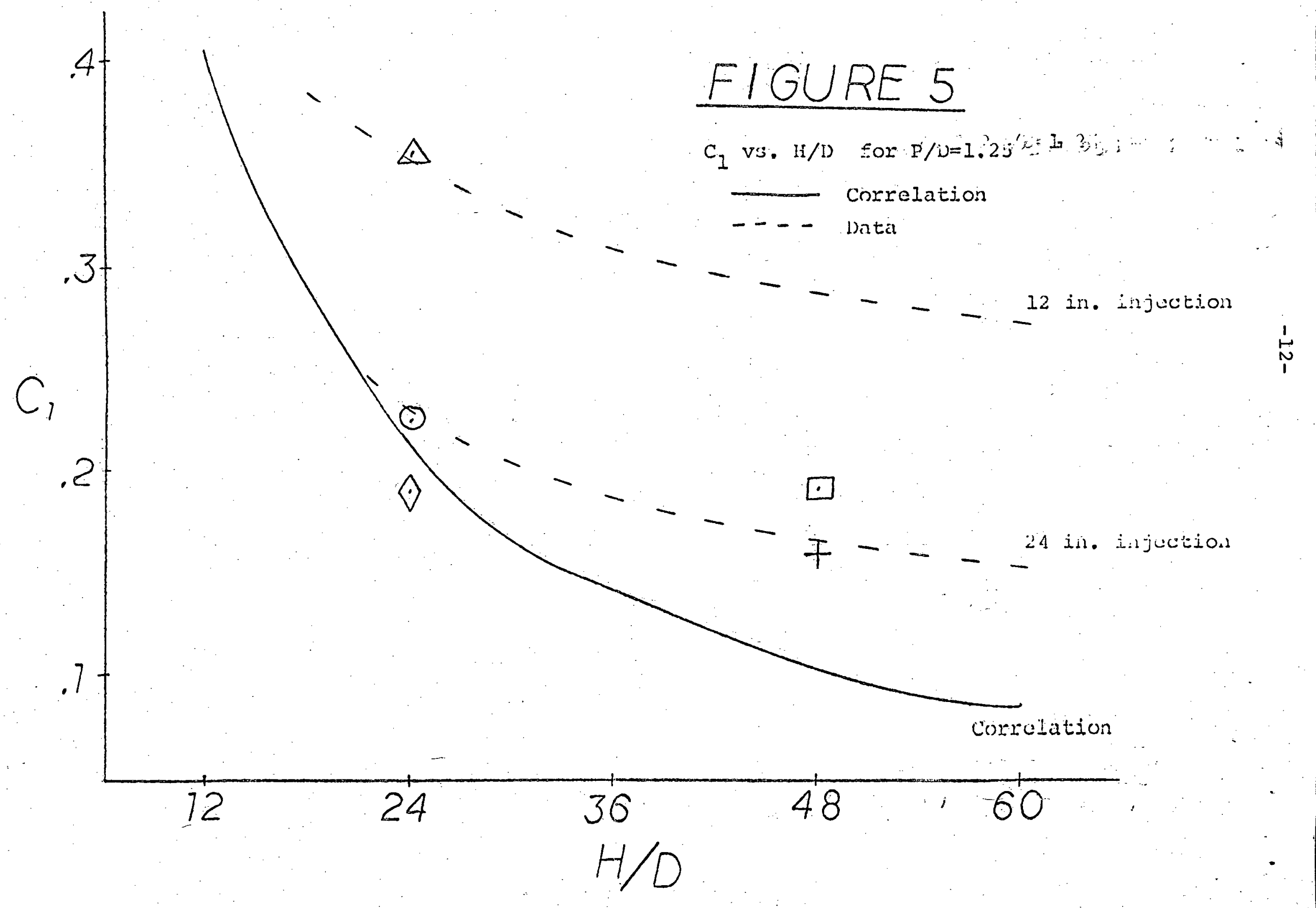




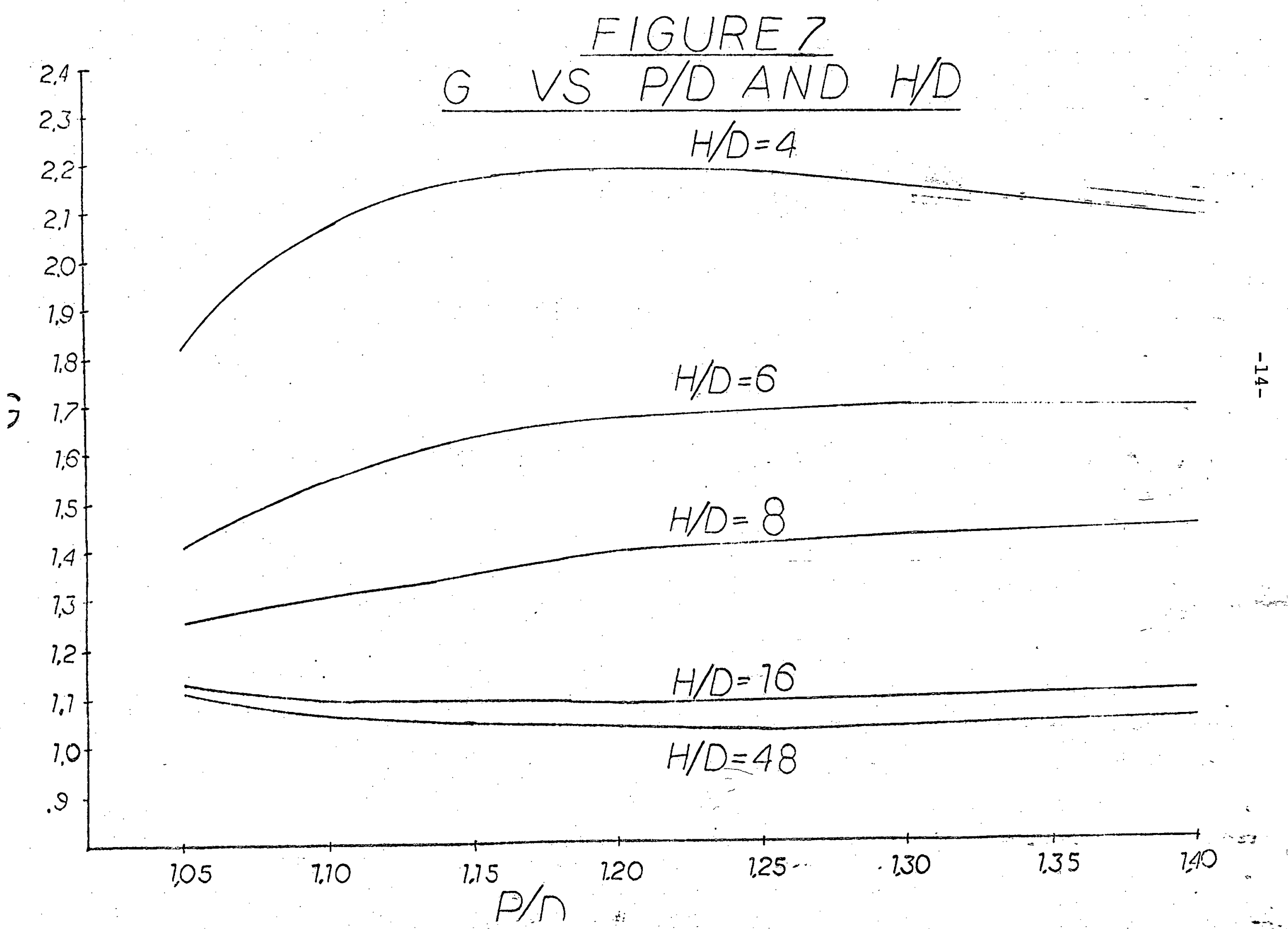




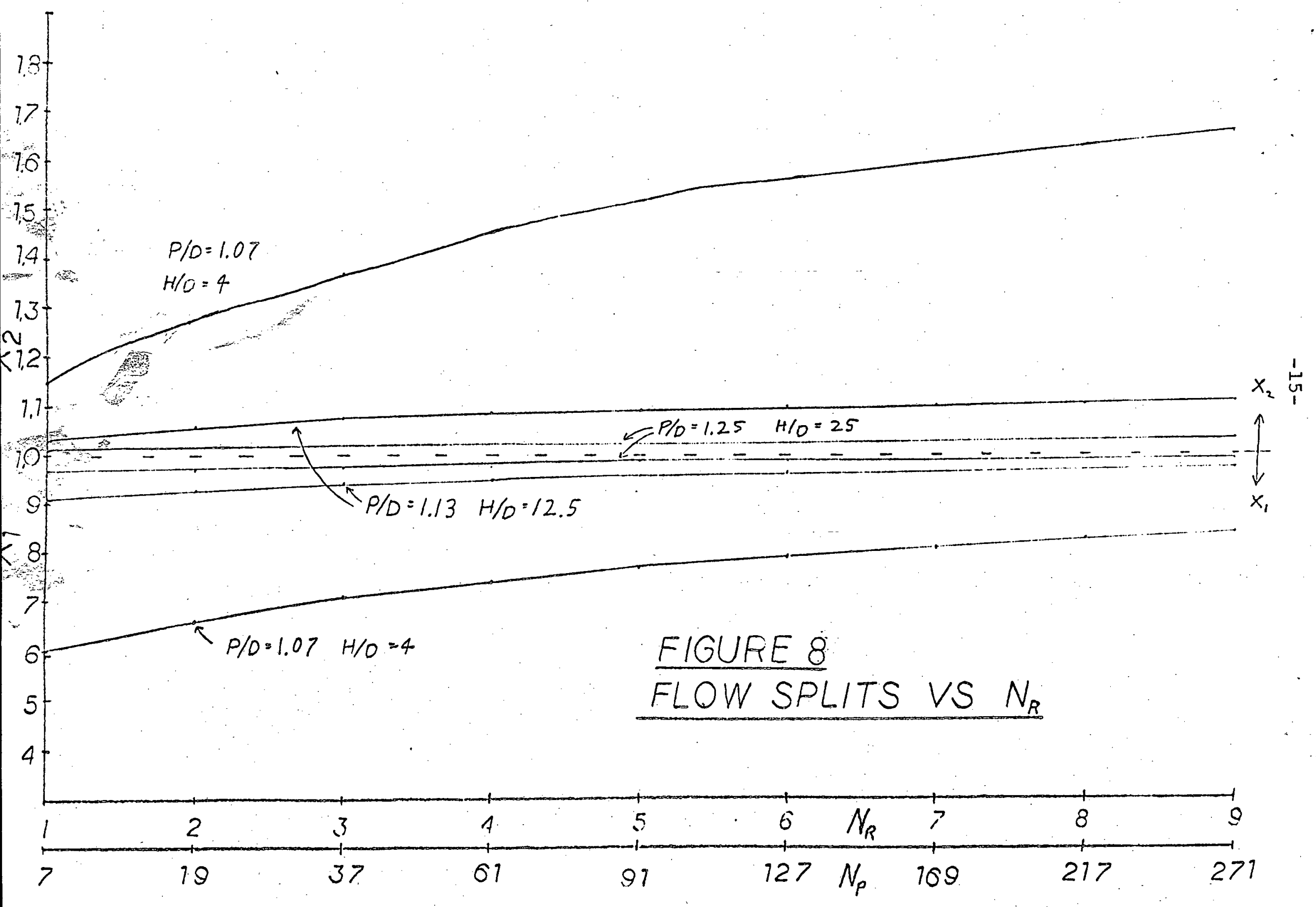


TABLE I

\begin{tabular}{|c|c|c|c|c|}
\hline TYPE & \multicolumn{2}{|l|}{ FUEL } & \multicolumn{2}{|c|}{ BLANKET } \\
\hline OPERATION & NORMAL & SHUTDOWN & NORMAL & SHUTDOWN \\
\hline PEAK POWER $\left(\frac{k w}{f t}\right)$ & 16 & --- & $7 \sim 16$ & --- \\
\hline $\begin{array}{l}\text { FLOW VELOCITY } \\
(\mathrm{ft} / \mathrm{sec})\end{array}$ & 25 & --- & $1.6 \sim 8$ & --- \\
\hline POWER/FLOW & 1.0 & $1.520 \quad$ (peak) & 1.0 & 1.969 (peak) \\
\hline${ }^{R a_{D}}$ & $\begin{array}{c}135 \quad \text { (based on } \\
\left.1000^{\circ} \mathrm{F}\right)\end{array}$ & $\begin{array}{c}205 \quad \text { (based on } \\
\left.1000^{\circ} \mathrm{F}\right)\end{array}$ & $\begin{array}{l}5500^{\sim} 12000 \\
\text { (based on } \\
\left.1000^{\circ} \mathrm{F}\right)\end{array}$ & $\begin{array}{l}11000^{\sim} 24000 \\
\text { (based on } \\
\left.1000^{\circ} \mathrm{F}\right)\end{array}$ \\
\hline$f / f_{i s o}(i n t)$ & 1.03 & 1.06 & $1.20 \sim 1.42$ & $1.40 \sim 1.75$ \\
\hline$f / f_{\text {iso }}$ (edge) & .94 & .95 & $1.50 \sim 2.00$ & $1.92^{\sim 2.83}$ \\
\hline
\end{tabular}


IB $6 \quad$ 37-Pin Blanket Bundle

(Tom Chiu)

Since the bundle was reassembled, the pressure drop experiment was done first because the experiment is relatively simple. Then the flow split experiment was underway. However, many difficulties were confronted.

The total mass balance in the flow split was found to be over $100 \%$ for the interior and the edge subchannels alone. The problem was found to be a result of the accuracy of the flow meter which indicated the total bundle flow rate. The flow meter indicated less than the actual flow rate. However, the defect is suspected to be on the range orifice inside the variable flow meter. The flow meter works on the principle that the flow rate is a function of the pressure drop across the orifice plate. Two pressure taps on both sides of the orifice plate are connected to a differential pressure gauge. The reading from the pressure gauge is then used to calculate the bundle flow rate. The calculated flow rate was compared to the actual flow rate by using a weight tank for flow rates up to $50 \mathrm{GPM}$. The calculated flow rate varies within $2 \%$ of the actual flow rate.

On the other hand, the flow split valules from the experiment do not follow the prediction of chiv's correlation. All possibilities are being explored. Also, the pressure drop results cannot be completely interpreted since the experimental flow split value is needed to calculate the subchannel friction factor and, hence, the bundle friction factor. Once the flow split experiments are completely done, the pressure drop data will be interpreted. 
ID.

Subehannel Code Development (Tóm Greene)

A ripiew of the SUPERENERGY predictions of the W-ARD Radial Blanjet Assembly Tests [1] has been done. The objective was to detefmine the cause of the discrepancies between the code predictions and the experimental data reported by $W-A R D$. A second set of code predictions has been made based on the results of the review.

The original predictions were made for four test runs, described in a preliminary test schedule from W-ARD. Only one of the four tests pre-predicted, Test Run 221, was actually performed. The SUPERENERGY predictions of this test were found to overestimate the temperatures in the bundle interior and underestimate the temperatures in the bundle periphery, in comparison to the reported experimental data.

Several problems in the pre-test predictions of Test Run 221 have been identified:

(1) The actual test operating conditions differed from the conditions reported in the preliminary test schedule. A higher flow rate and a lower power in the actual test run caused the experimentally-measured temperatures to be lower than the code predictions. Table I summarizes the operating conditions for Test Run 221, as reported in the preliminary schedule and as actually performed.

(2) The flowsplit and mixing parameters were evaluated at the Reynolds number corresponding to the inlet coolant temperature. These values were assumed to apply over the entire assembly length. The strong temperature dependence of viscosity for sodium causes the Reynolds number to increase over the heated length of the assembly. Table II summarizes the change in Reynolds number for this test case, and the resulting change in the flow split and mixing parameters. 
(3) Calculational Errors resulted in errors in the code input parameters. An error in the calculation of the Reynolds number resulted in errors in the flow split and mixing parameters.

Predictions have been made for five of the tests actually performed, including Test Run 221, which was included in the pretest predictions. These predictions used the actual operating conditions for the test, as reported by $W-A R D$ [2], as code input. In addition, the flow split and mixing parameters were evaluated at the Reynolds number corresponding to the average bundle temperature. Figures 1-4 compare the pre-test and post-test predictions to the reported experimental data for Test 221. These figures show that the new predictions overestimate the reported bundle interior temperatures and underestimate the reported temperatures in the bundle periphery, although to a lesser degree than the pre-test predictions. Code runs were made with the input parameters at their uncertainty limits to determine the uncertainty in the code temperature predictions due to input parameter uncertainties. The results are shown as error bands in Figures 1-4. As shown in the figures, the input parameter uncertainties do not account for all the differences between the code predictions and the data. A possible cause for these discrepancies is that a uniform heat flux distribution around the heater rods was assumed. In reality, the cross-bundle power skew and the flow split between interior, edge, and corner channels cause circumferential variations in temperature around the heater rods. These temperature variations induce a circumferential skew in the heat flux which acts to oppose the temperature variations, 
i.e, the heat flux will be higher in low temperature regions than in higher teimperature regions. The magnitude of this effect in the $W$-ARP heater rods should be investigated to determine if it can explain the observed discrepancies between the SUPERENERGY code and the reported W-ARD data.

$$
\text { : } \operatorname{xis}
$$

\section{TRANSENERGY Códe Development}

Progress on the multi-assembly version of the TRANSENERGY code will be included in the next progress Report.

\section{REFERENCES}

1. Chiu, C. and Todreas, N., "W-ARD Blanket Assembly Pretest Predictions by SUPERENERGY," COO-2245-40TR, MIT, May 1977.

2. Yerace, J., "Radial Blanket Assembly Heat Transfer Tests in Sodium. Transmittal of Results of 15 Powered Tests, March 1979. 
980
O POST TEST PREDICTIONS

GEO $\triangle$ EXPERIMENTAL

940

920

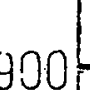

는 $840-$

竞

820

800

8005

780

750

$740-\triangle \triangle$

$720-$

$700-$

680

660

640
RUN 221

LEVEL AA (EXIT HEATED REGION)

ERROP BARS FOR FLOWSPLIT

ONLY. $\varepsilon_{I}^{*}$ NOT INCLUDED.

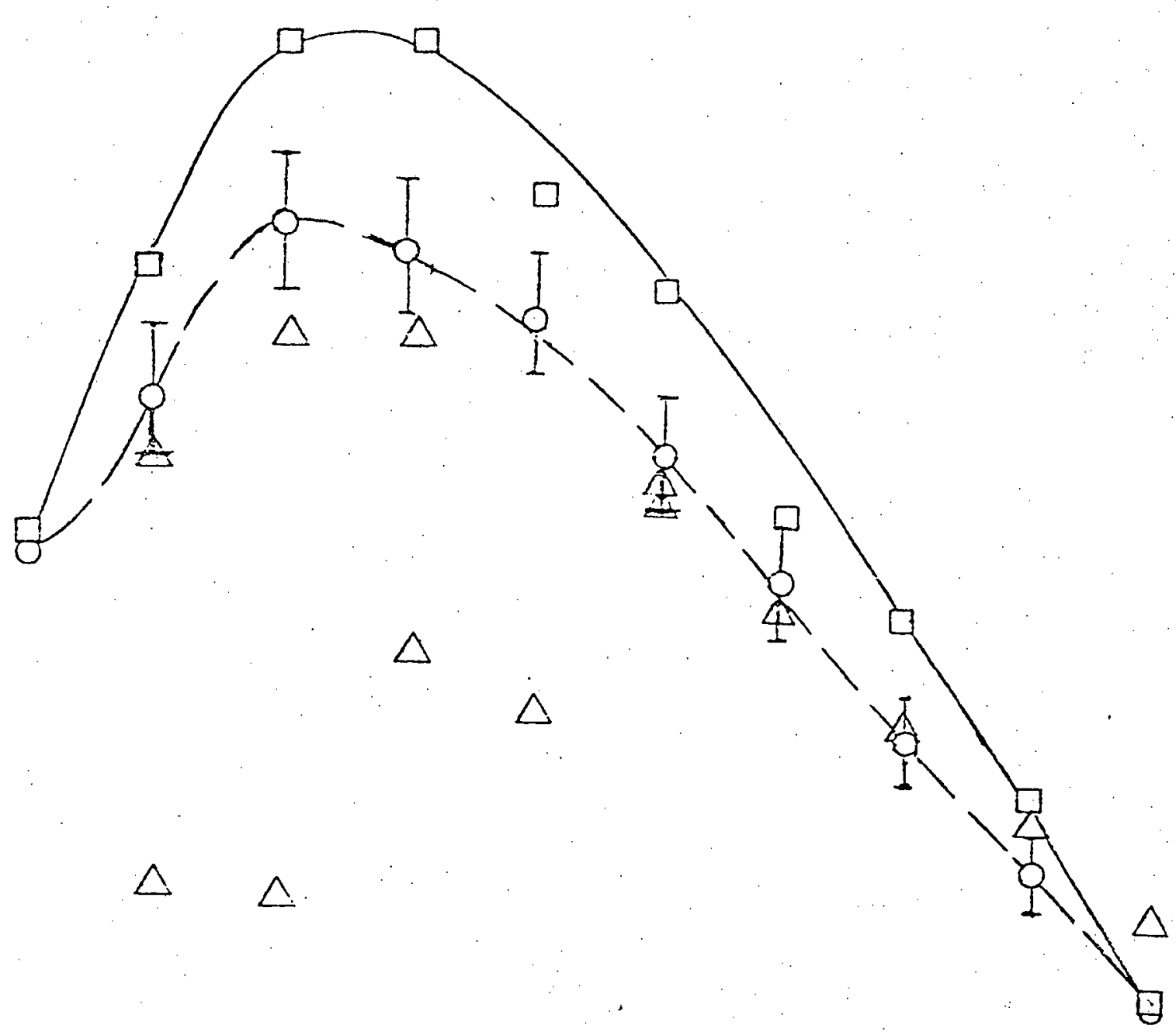




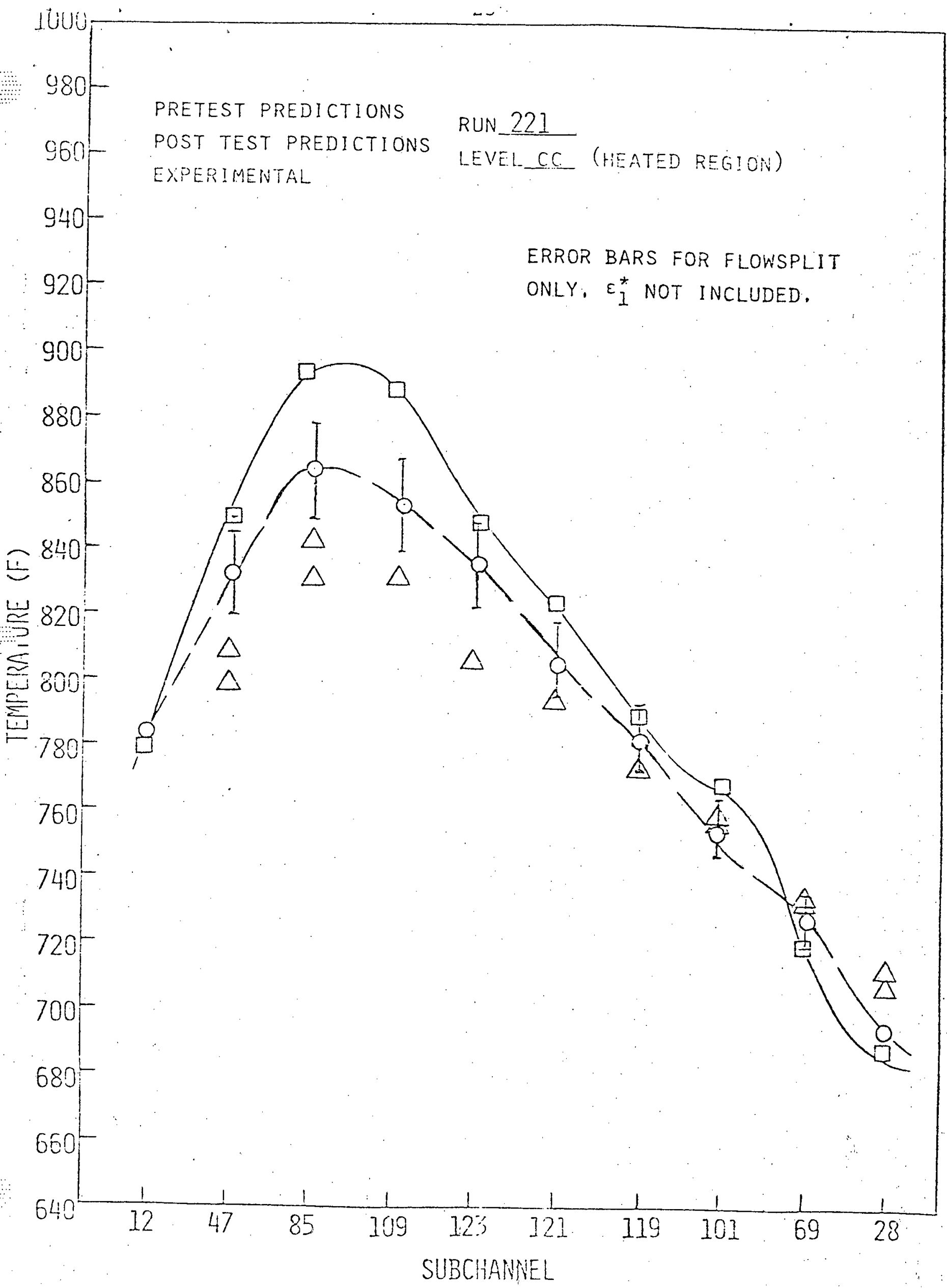

Figure 3. CROSS-BUNDLE TEMPERATURE PROFILE

8.0 in. BELOW HEATED ZONE 


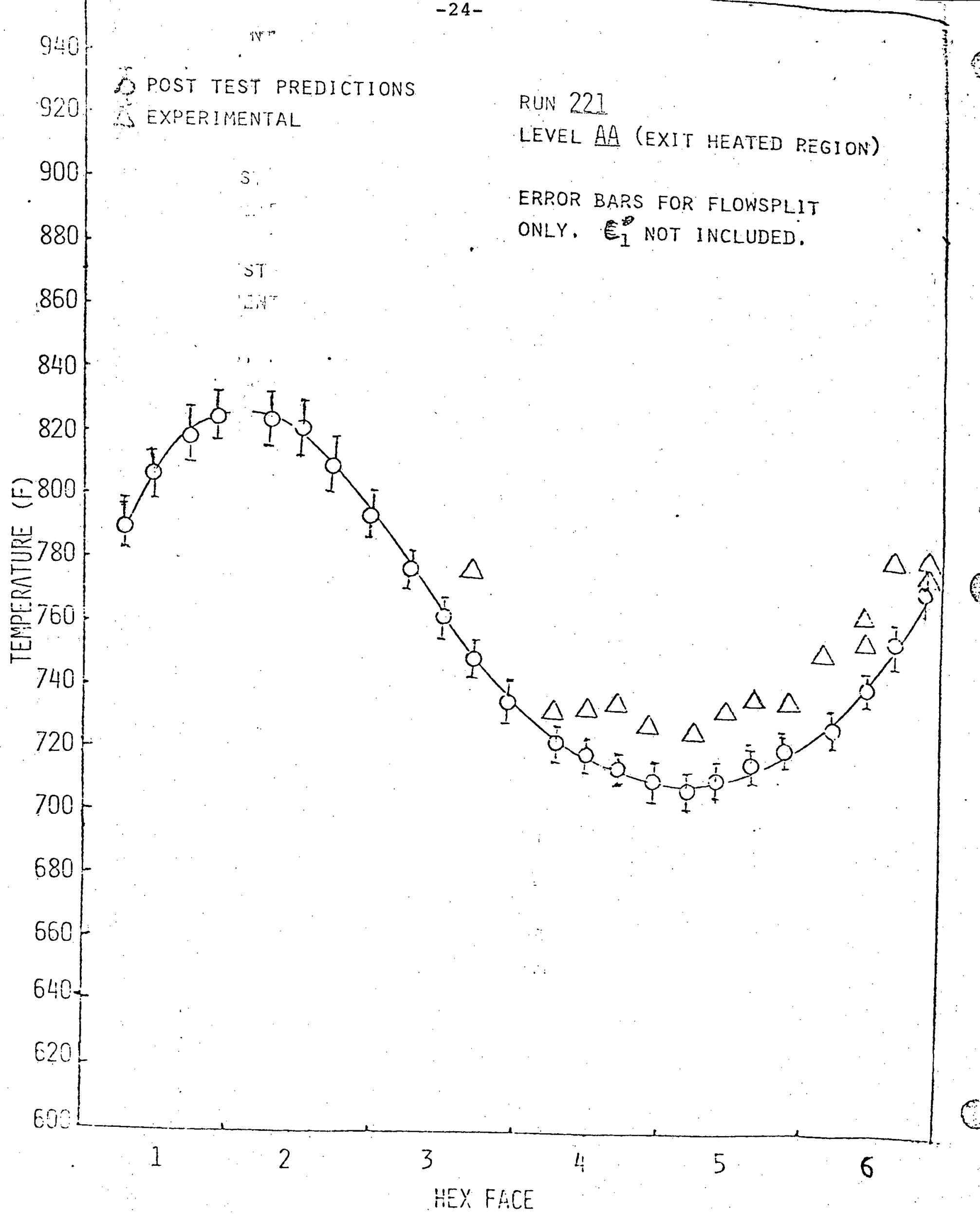

RUN 221

LEVEL AA (EXIT HEATED REGION)

ERPOR BARS FOR FLOWSPLIT ONLY, NOT INCLUDED. 


\begin{tabular}{|c|c|c|}
\hline & $\begin{array}{c}\text { PRELIMINARY } \\
\text { TEST PLAN }\end{array}$ & ACTUAL TEST \\
\hline $\begin{array}{c}\text { POWER } \\
(\mathrm{kW})\end{array}$ & 132 & 129.7 \\
\hline $\begin{array}{c}\text { FLOW } \\
(1 \mathrm{bm} / \mathrm{hr})\end{array}$ & 7400 & 7962 \\
\hline
\end{tabular}

TABLE I

Comparison of Operating Conditions for Test Run 221 (Preliminary Schedule vs. Actual Test)

\begin{tabular}{|l||c|c|c|}
\hline & BUNDLE INLET & BUNDLE. AVERAGE & BUNDLE EXIT \\
\hline \hline TEMPERATURE & $603^{\circ} \mathrm{F}$ & $693^{\circ} \mathrm{F}$ & $783^{\circ} \mathrm{F}$ \\
\hline$N_{R E}$ & 3909 & 4350 & 4782 \\
\hline$x_{1}$ & .785 & .801 & .812 \\
\hline$X_{2}$ & 1.400 & 1.364 & 1.345 \\
\hline$x_{3}$ & $1.400^{(a)}$ & $1.364^{(@)}$ & $1.345^{a}$ \\
\hline$\varepsilon_{1}^{*}$ & .285 & .300 & .310 \\
\hline$c_{1}$ & .315 & .325 & .338 \\
\hline
\end{tabular}

(a) corner flow split, $x_{3}$, assumed equal to edge flow split, $x_{2}$.

\section{TABLE II}

Variation of Reynolds Number, Nominal Flow Splits, and Nominal Mixing Parameters Due to Temperature Variation. Evaluated for Test Run 221. 
$n^{2}$

$\therefore$

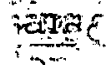

ei

ID.2 Mixed Convection in Sodium-Cooled Reactors under

Transients

(Song-Feng wang)

Thedanalytic solution of subchannel friction factors for laminaronvective upflow in a hexagonal rod bundle has been obtaiñed. The behavior of subchannel friction factors due to the presence of buoyant forces was investigated and the results of that will be used in the THERMIT post-test runs for BNWL $2 \times 6$ mixed convection experiments.

In Figure 1, symmetric sections of the interior, edge; and corner subchannels, known as a cell, are shown. The velocity and temperature fields within these cells were analyzed using a multi-region analytical method (1). The axial momentum equation was solved analytically, together with the energy equation for fully-developed laminar upflow: The buoyancy effects were included by keeping the body force in the momentum equation. Figure 1 also gives the general assumption we made in the analysis. The validity of these assumptions will be discussed later. Although the computational procedures are the same for all cells, only interior and edge cells were analyzed. The resultant subchannel friction factors are given in Figures 2, 3, 4, 5, and 6 .

Figure 2 shows the subchannel friction factors when buoyant forces approach zero. The comparison between present results and previous studies (2) for isothermal laminar upflow assures the validity of the present analysis.

Figure 3 shows the friction factor for interior subchannel. It monotonically increases with increasing buoyant forces. This is because the velocity gradient near the heating surface, and 
hence the wall shear stress, increases due to the presence of buoyant forces. With increasing $P / D$ ratio, this distortion of the velocity profile is gradually enhanced and therefore, the increase in friction factor is more pronounced.

The behavior of friction factors for edge subchannels, shown in Figure 4 , is more complicated than that for interior subchannels due to the non-symmetry of the edge subchannel. geometry. There are two components of the friction factor in the edge subchannel - one for rod surface and the other for duct wall. When buoyancy effects become important, coolant flow redistributes itself from duct wall toward rod regions to conserve the mass flow rate. This flow redistribution gives rise to a shift in the wall shear stress and hence the "sadale" behavior of the friction factor which gradually decreases in the beginning and then increases with increasing buoyant forces. When buoyant forces are negligible, laminar flow remains laminar in a rod bundle. However, as the buoyant forces become: important, the increase of the wall shear force generates turbulence near the rod surface and the flow becomes turbulent. The criteria for this transition from laminar to turbulent flow. can be determined by forcing the maximum allowable wall shear stress for mixed convective flow to be the same as the critical wall shear stress for isothermal flow. The corresponding maximum allowable flow rate then determines the criterion for transition. It is a function of power level. In Figures 3 and 4, $16 \mathrm{kw} / \mathrm{ft}$ was used to simulate the upper limit of the fuel and blanket operation conditions. For lower power level, transition occurs at higher velocity (flow rate) and the curves for $I_{\text {max }}$ 
corresponding to maximum allowable wall shear stress, move toward the left. For zero power, $L_{\max }$ becomes $f_{o}$, the isothermal subchannel friction factor.

Figure 4 also shows the onset of flow recirculation where the fiow near the duct wall becomes stagnant (and then flows downward for increasing buoyant forces). The occurrence of flow circulation sets the limit on using a lumped parameter approach to model the subchannel. Any analysis beyond this limit should be done in a distributed parameter way, i.e., distributed parameter analysis, because in lumped parameter analysis only one velocity and one temperature value is assigned in each subchannel which makes it unable to handle flow recirculations. For large $P / D$ ratio, flow tends to become turbulent before recirculation occurs, while for small P/D ratio, the reverse is true.

Figures 5 and 6 are the cross-plot of Figures 3 and 4 , respectively. The variations of subchannel friction factors with buoyant forces are plotted for different $P / D$ ratios. In Figure 6, the saddle behavior of edge subchannel friction factor can easily be seen for $P / D<1.35$.

Table I shows the typical normal and shutdown operation conditions for CRBR power plant. The corresponding Rayleigh numbers, based on rod diameter, for fuel and blanket bundles are also shown in the Table. According to present analysis, the buoyancy effect on friction factors is not negligible for blanket bundles, while it is negligible for fuel bundles. This is true for both normal and shutdown conditions. However, since 
the general assumption we made in the analysis is subject to some questions (see next paragraph), the results presented here are for reference only and subject to further verification.

There are two critical assumptions we have made in this analysis: (1) in the "fully-developed" assumption, (Figure 7), the velocity profiles are similar and the temperature and pressure gradients in the axial direction are constant for successive axial positions. It is true only if the density is a linear function of temperature and viscosity is independent of temperature; (2) in the "isolated cell" assumption, the heat transfer across the boundary and shear stress along the interfaces are neglected. However, this is not the case when buoyant effects become important. It is expected that the "adiabatic" boundary condition on the temperature field could introduce some errors in the friction. analysis, but accommodation of coupled cell effects severely complicate the analysis. We will examine the extent to which the isolated cell friction results can be applied to real. situations. All the pressure drop behavior and onset of flow recirlation will be studied for downflow situations in order to handle the situations in which complete flow reversal has occurred. Figure (8) schematically illustrates the differences between the upflow and the downflow situations. 
1. J. Kim and L. Wolf, "Fully-Developed Mixed Convection Heat Transferin the Finite Hexagonal Bundles," M.S. Thesis, Nuclear, Engineering Department, MIT (February 1977).

2. E. M. Sparrow and A. L. Loeffler, Jr., "Longitudinal Laminar Flow Between Cylinders Arranged in Regular Array," JAIChE, $5,325^{-1}$ (1959).

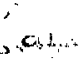

$\rightarrow+$ 


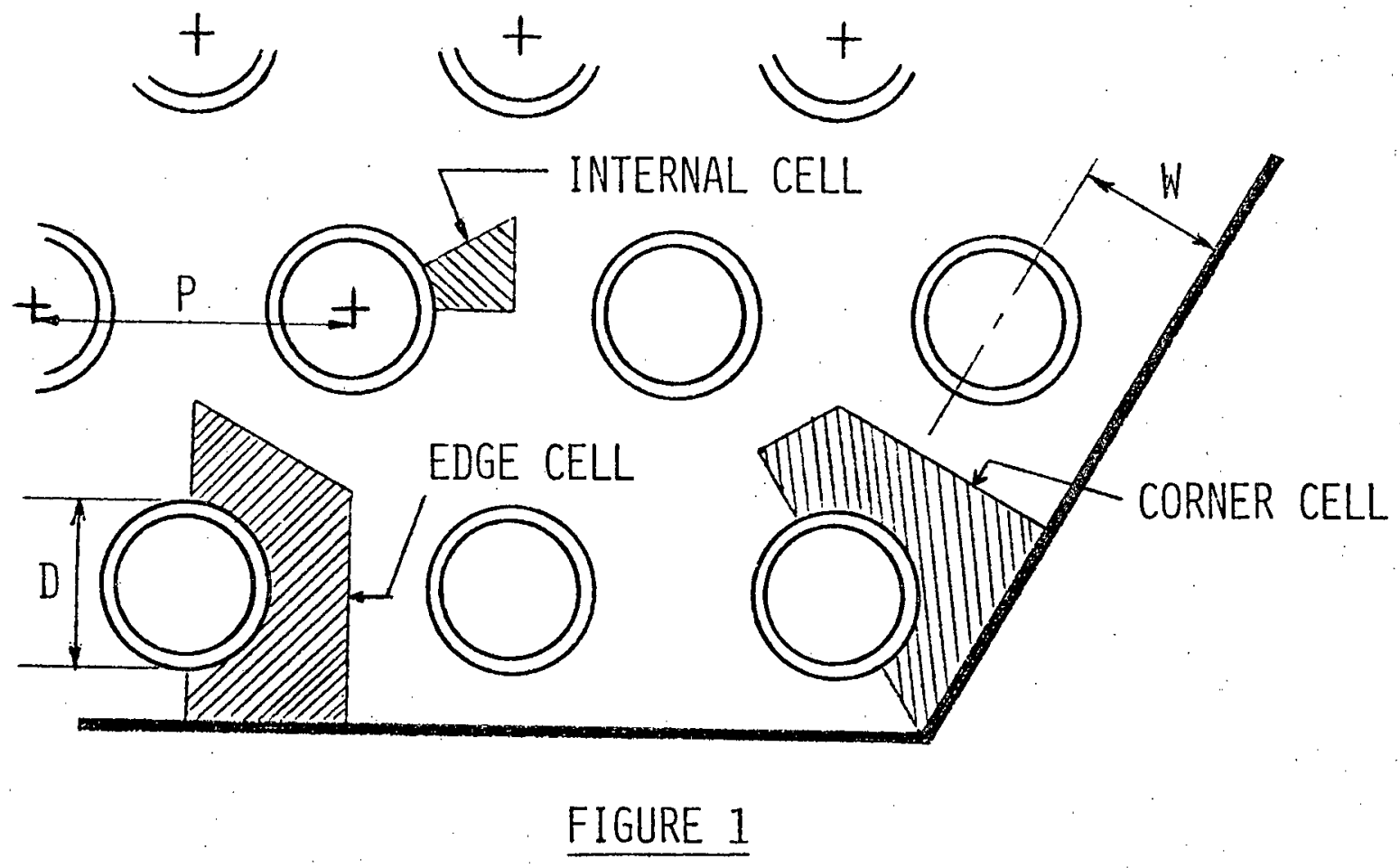

GENERAL ASSUMPTIONS

- bare rod bundLe

- ISOLATED CELLS

- THERMAL 2-REgION PROBLEM (CLAD + COOLANT)

- THERMALLY AND HYDRODYNAMICALLY FULLY-DEVELOPED LAMINAR FLOW

- CONSTANT PHYSICAL PROPERTIES EXCEPT P IN THE MOMENTUM EQUATION

- NO AXIAL CONDUCTION, PRESSURE WORK, AND VISCOUS DISSIPATION

- NO HEAT SOURCE IN CLAD AND COOLANT

- STEADY STATE 
FIGURE 2. FRICTION FACTORS FOR ISOTHERMAL FULLY-DEVELOPEDD

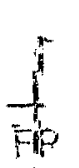

LAMINAR FLOW IN BARE ROD BUNDLES

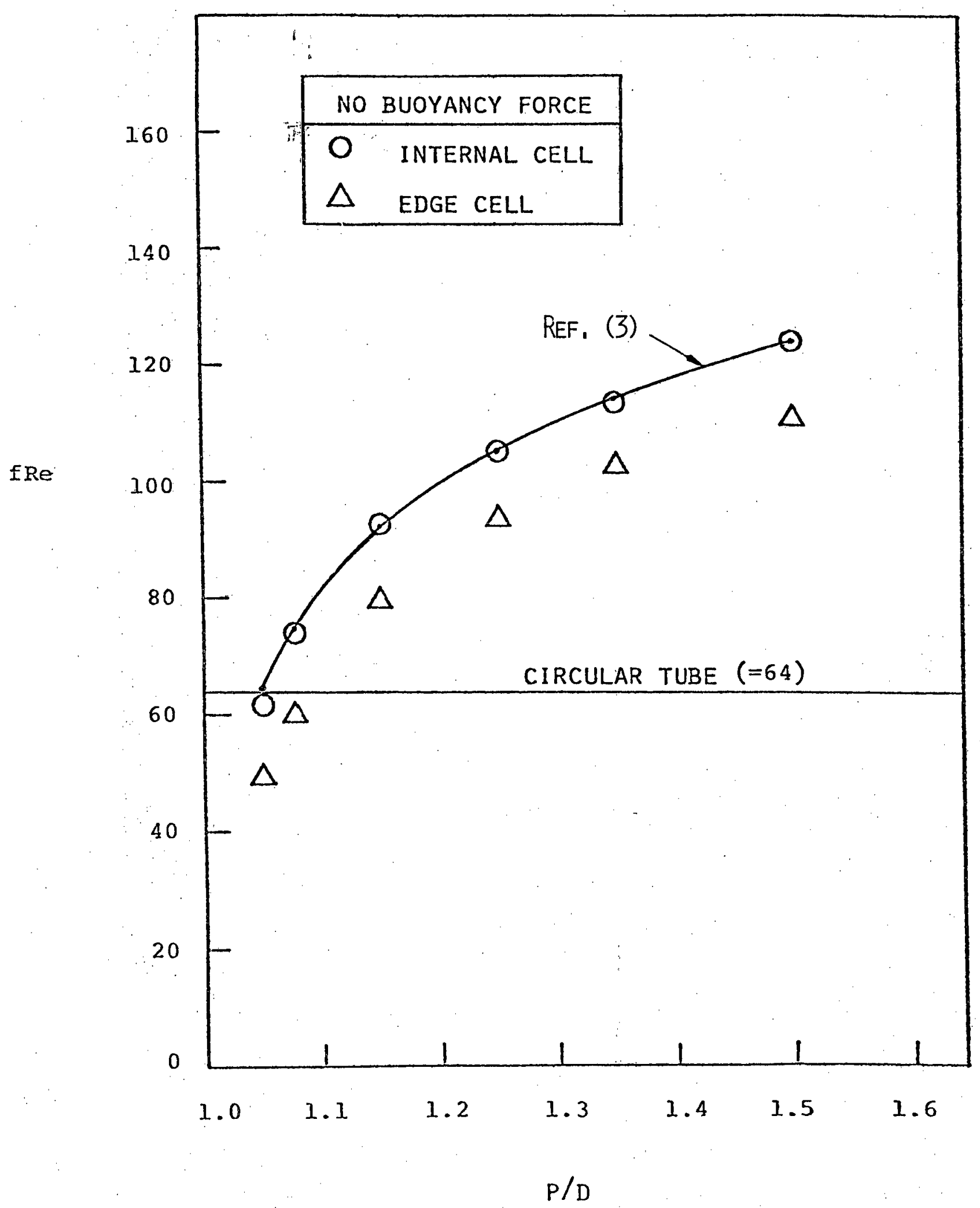




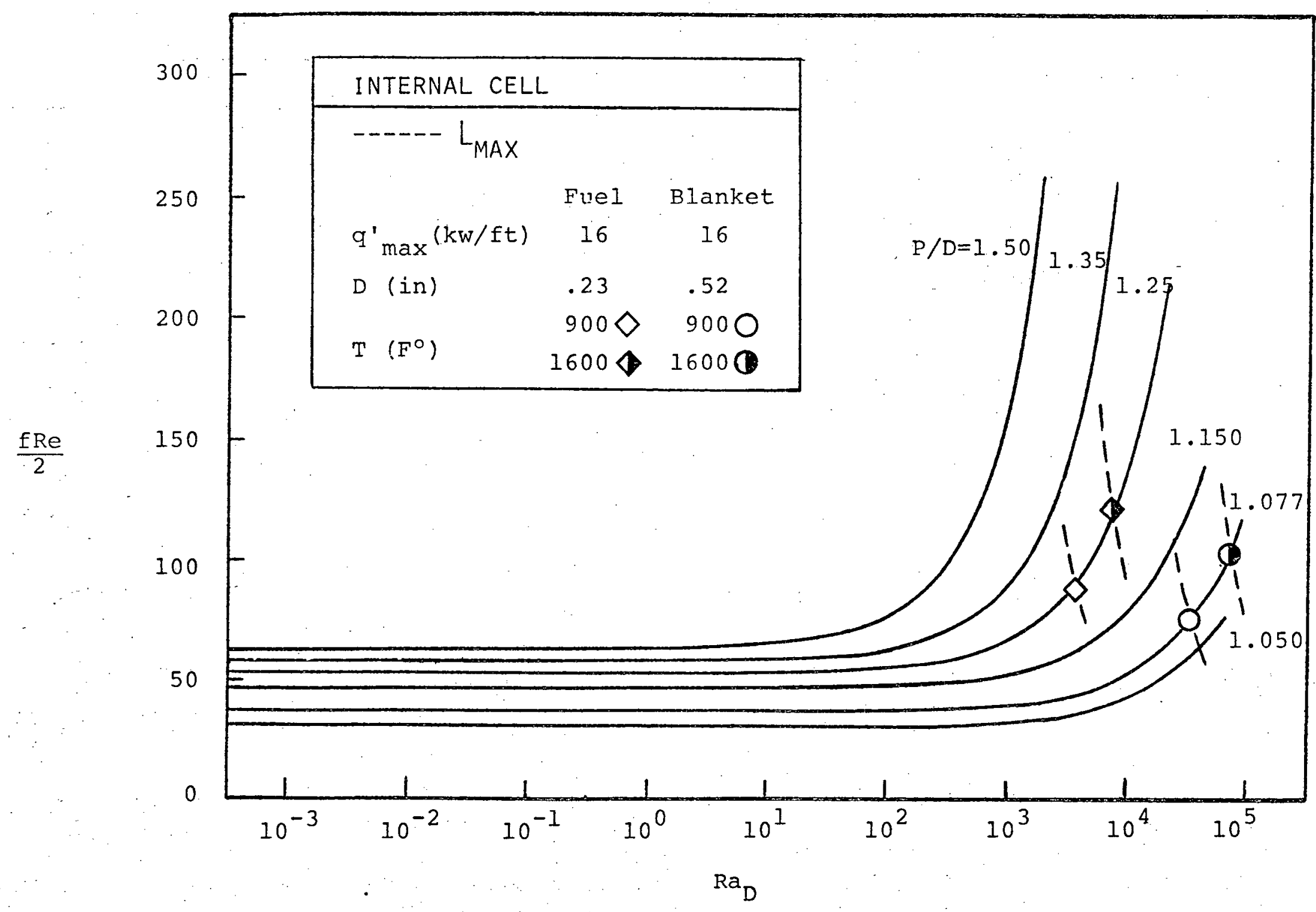

FIGURE 3. FRICTION FACTOR FOR FULLY-DEVELOPED LAMINAR FLOW IN BARE ROD BUNDLES 


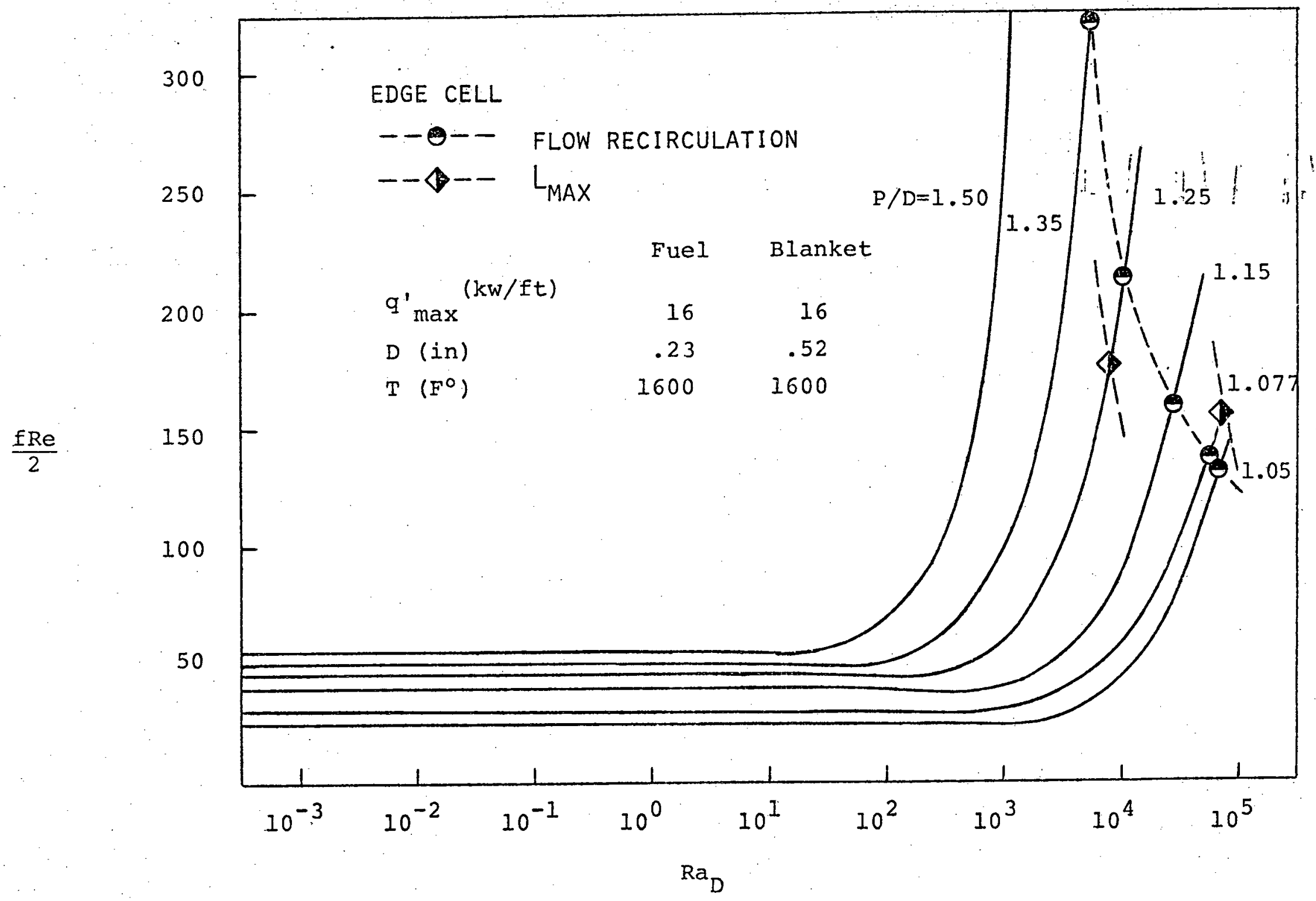

FIGURE 4. FRICTION FACTOR FOR FULLY-DEVELOPED

LAMINAR FLOW IN BARE ROD BUNDLES 


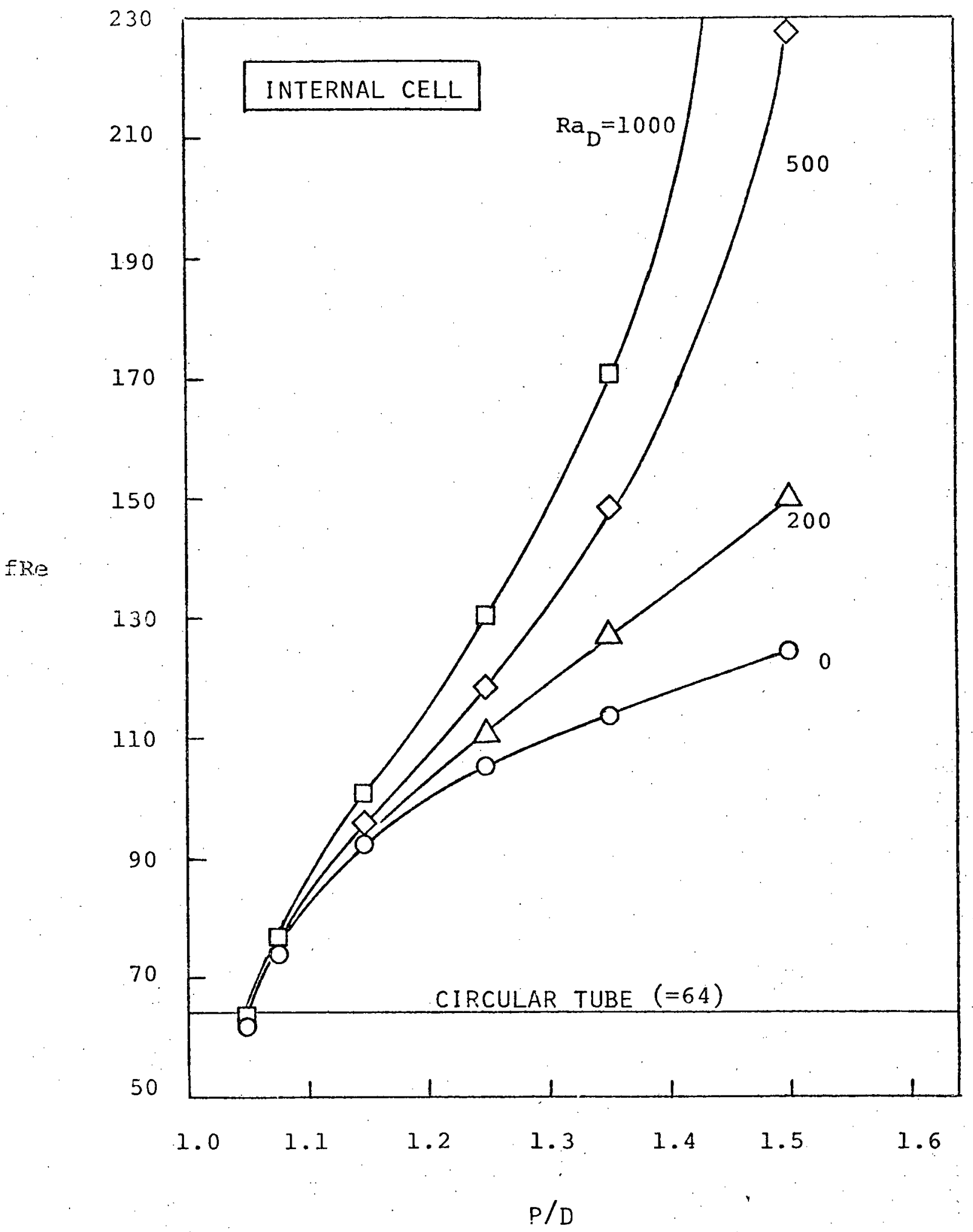

FIGURE 5. FRICTION FACTOR FOR FULLY-DEVELOPED LAMINAR FLOW IN BARE ROD BUNDLES 


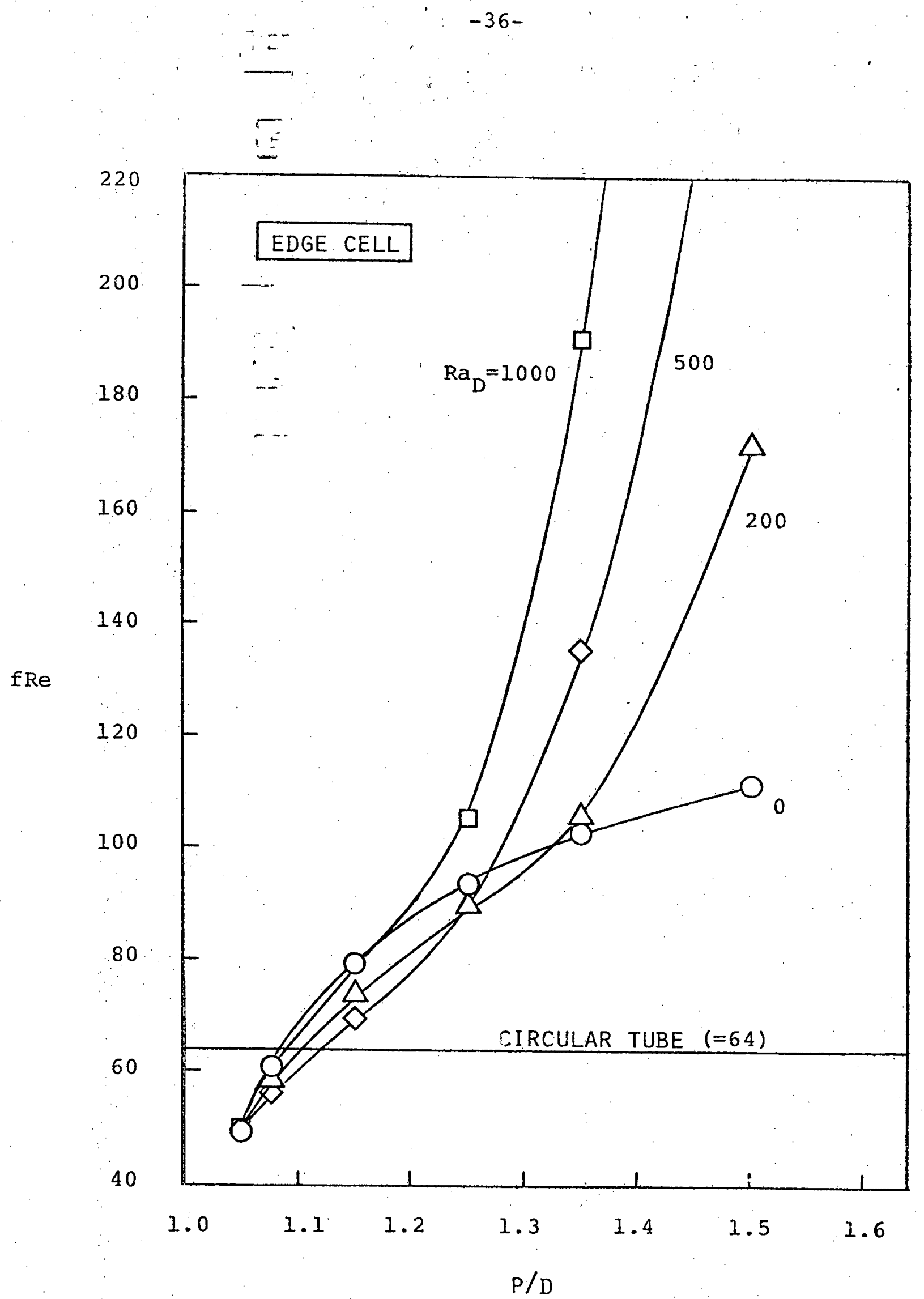

FIGURE 6. FRICTION FACTOR FOR FULLY-DEVELOPED LAMINAR FLOW IN BARE ROD BUNDLES 


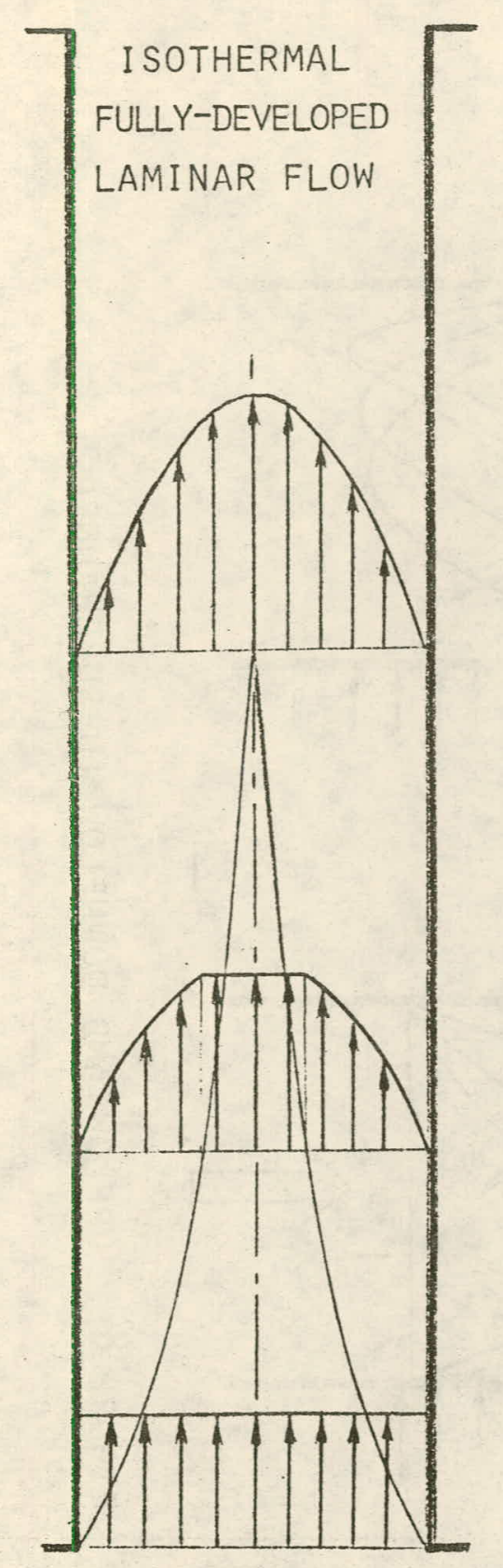

LOW $U_{\infty}$

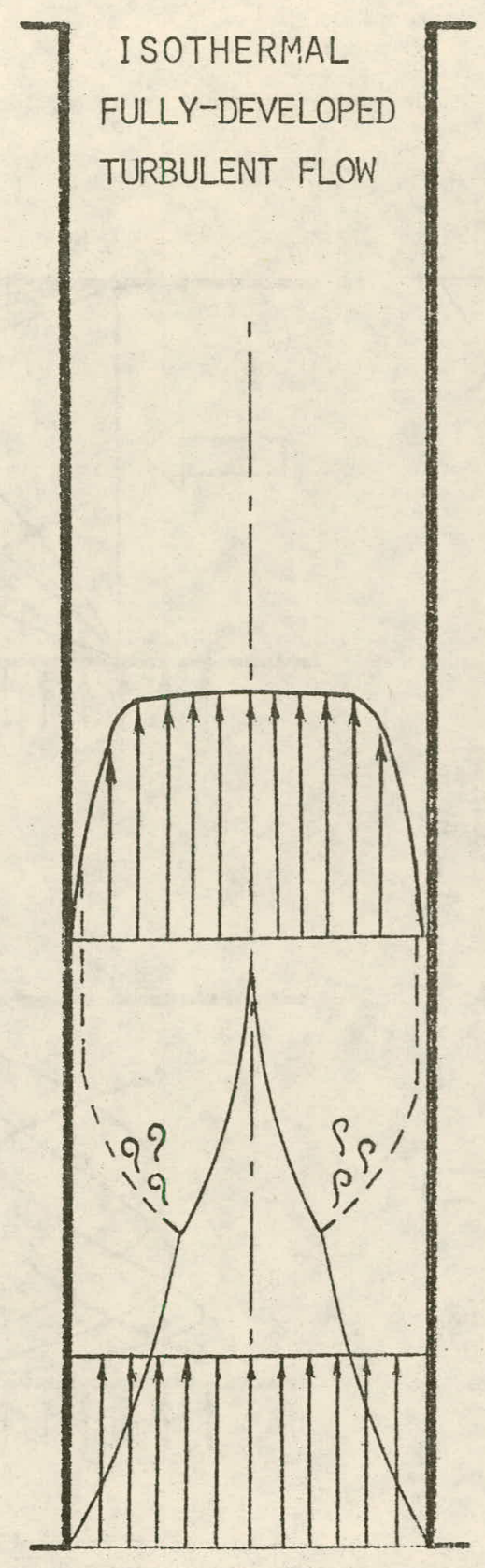

$\mathrm{HIGH} U_{\infty}$

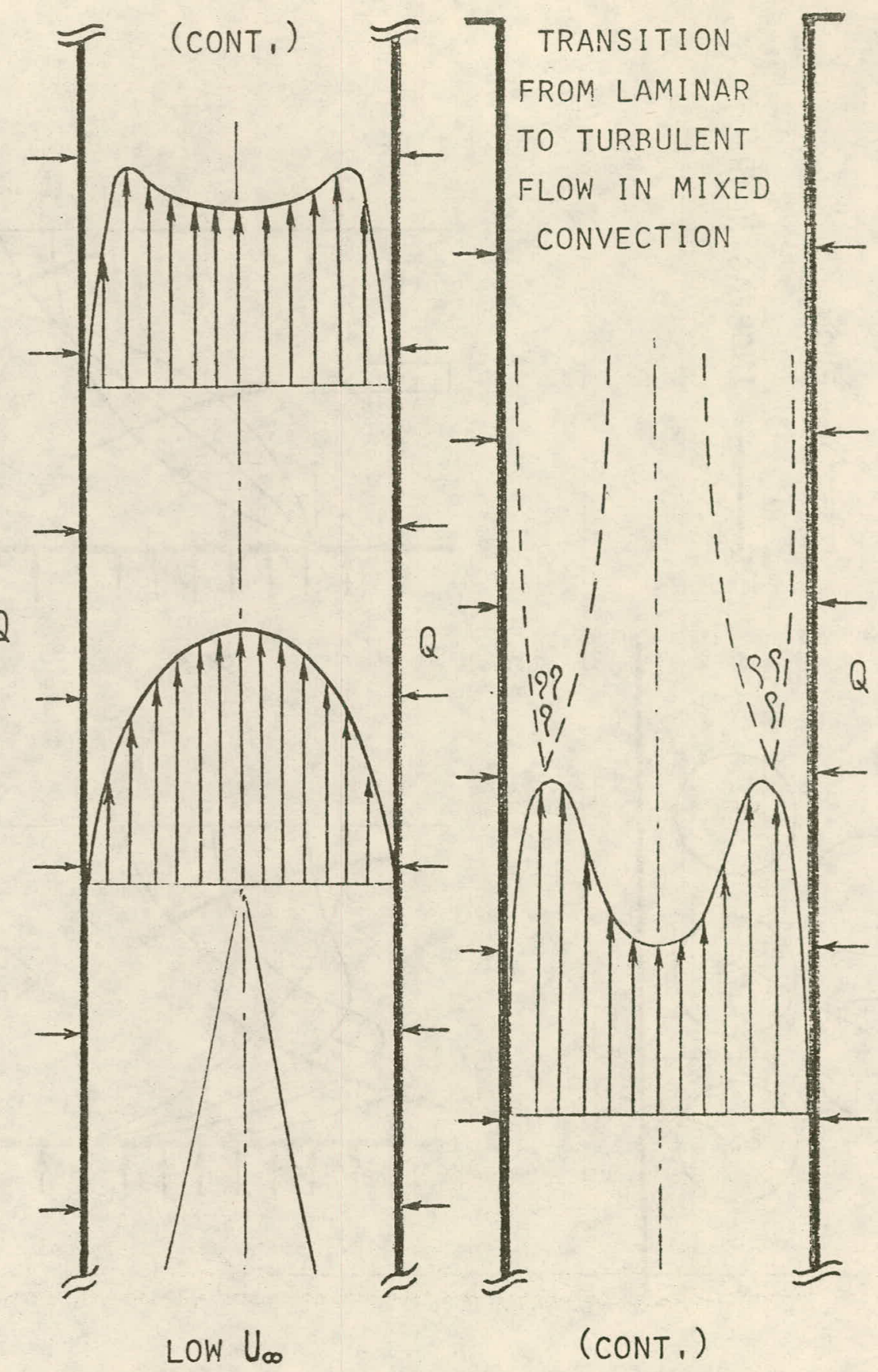

$\stackrel{1}{w}$

FIGURE 7. DEVELOPING AND FULLY-DEVELOPED FLOW IN CIRCULAR TUBES 


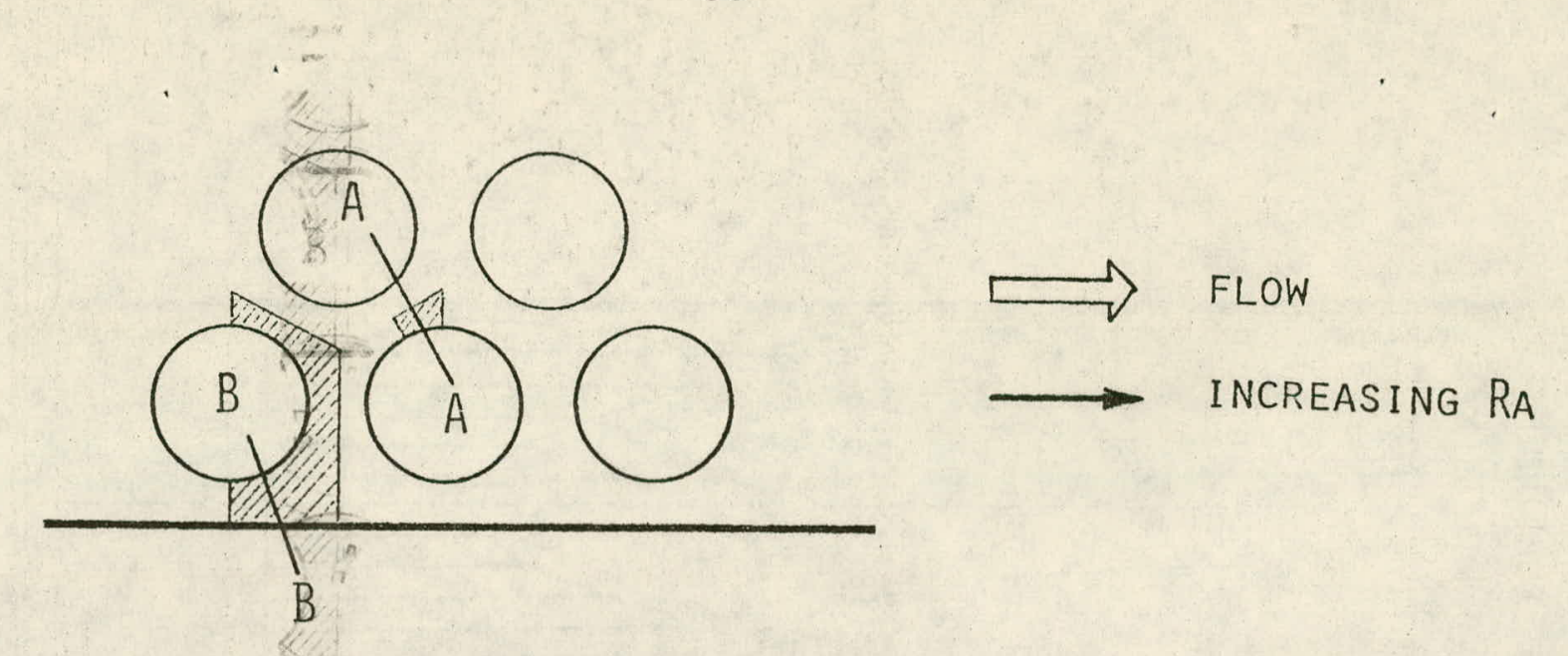

Q
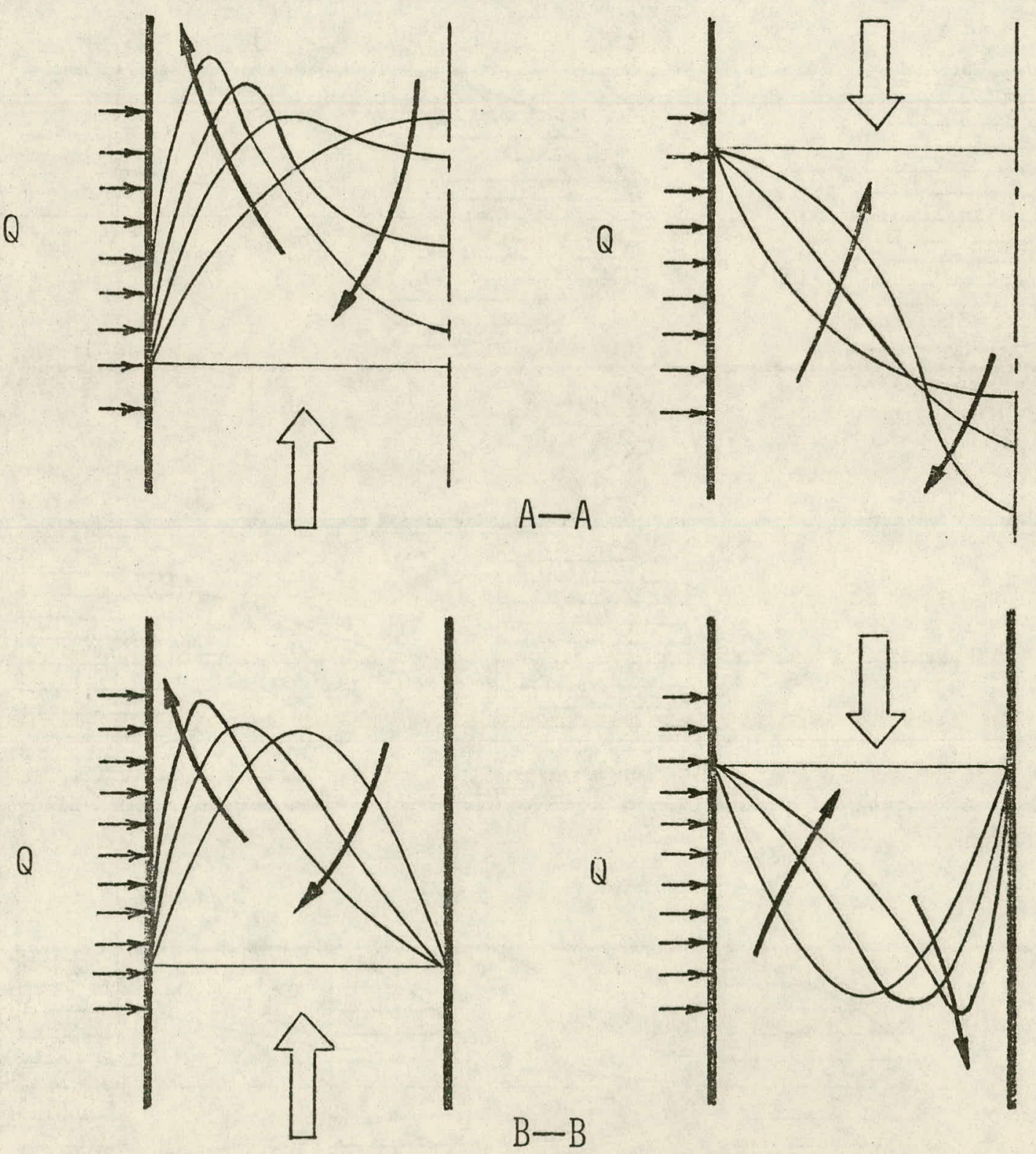

FIGURE 8. UPFLOW AND DOWNFLOW IN SUBCHANNEL 
TASK III: LMFBR OUTLET PLENUM FLOW MIXING

III.1 Transient Effects in Turbulence Modeling

(D. Boyle)

Progress to Date

Achievements during this period fall into three areas: equipment, experimental method, and computer code refinements. The in-house analog-to-digital converter and recording device has been completed and tested and its major features are described below. Questions concerning the accuracy of the experimental hardware and measurement technique arose during the period and are addressed in this report. Finally, the VARR-II code has been modified to include an additional turbulence model as a userselectable option.

\section{Equipment}

The custom Analog-to-Digital data recording system, required for transient measurement, has been completed and fully tested. This equipment, produced in-house, samples and records the five analog voltages output from the Laser Doppler Anemometer that define the turbulence field parameters at a point in the cell as a function of time. Designed with a high degree of flexibility to accommodate a variety of inlet voltages, the system has demonstrated errors of less than $1 \%$ for all five channels. The builder of this device is currently producing a detailed documentation package to insure effective use of the system in future LDA experiments that are now in the planning stage. Use of the system in the current experiment has been tested, and the data tapes produced interface smoothly with the data-analysis and display 
programs written for the Textronix mini-computer.

Experiment

Two items relating to experimental accuracy are of interest: (a) the method of ensemble averaging, and (b) continuity checks on overall ceil velocity measurements.

Item (a), refers to the problem of measuring average values of fluctuating quantities during a transient. The method proposed is to form ensemble, or probability, averages from values obtained by monitoring the output voltage of an integrator whose averaging time is small with respect to the time scale of the transient and large with respect to the time scale of the fluctuations. The ensemble is obtained by repeating the same transient a suitable number of times. In theory, given the nature of the analog devices.used to perform the time-averaging, this method will be successful when the fluctuations are Gaussian. ${ }^{1}$ However, since turbulence fluctuations are only approximately Gaussian, a simple experiment was performed to determine the magnitude of the error introduced by use of this technique. Accordingly, the standard turbulence quantities were measured one inch above the chimney inlet at full steady-state flow, and averaged in two different ways. The experiments produced a negligible difference between the true time-average and the pseudo-ensemble-average values for both mean velocities and turbulence intensities at the averaging times relevant to our experiment.

\footnotetext{
1" Mathematical Analysis of Random Noise," S.O. Rice in Noise and Stochastic Processes, Editor: Nelson Wax, Dover Publications, NY, NY (1954).
} 
(b) Cell-scale continuity checks were performed to determine the extent to which modifications to the test cell have reduced or eliminated discrepancies found in the data of chen (COO-2245-44TR). Lack of flow symmetry in the unmodified testcell used by chen is believed to be the major reason that cell-scale mass balances obtained from his data are not consistent. For example, comparing vertical velocities measured by chen across the cell from side-wall to centerline yields a mass defect (upflow less downflow) of $25 \%$ at a plane located an inch above the chimney inlet and $81 \%$ at a plane near the top of the cell. The same measurements performed on the modified cell (modifications described in the last progress report) yield an essentially negligible mass defect of $4 \%$ at the centrally located plane, and a significant 50\% at the uppermost measurement plane. While the improved flow symmetry obtained in the modified cell yields a major increase in the data quality throughout' most of the cell, the three dimensional effects occurring near the top are seen to influence the mean flow data strongly in that region. Therefore, predictions by two-dimensional fluid dynamics codes, such as VARR-II, would not be expected to conform to the measurements made in this part of the test-cell.

Another area of concern regarding Chen's data was that the highly-peaked velocity distribution at the inlet exhibited an inflection point indicating that the flow was not fully developed. As is discussed in the last report, this condition contributed 
to the anisotropy of the turbulence in the inlet region, and has been remedied by the modifications performed on the new cell. (See plot of inlet velocity distribution in the previous Progress Report.)

Computer Worje

The VARR-II computer code uses a two equation scalar turbulence model based on the transport of the quantities $\mathrm{K}$ (turbulence kinetic energy) and $\sigma$ (turbulence viscosity), the so-called "K- $\sigma$ " model. Two-equation models of turbulence have been suggested for recirculating flow problems because of the requirement to account for the transport of the turbulence length scale, as well as the turbulence velocity scale, in this type of flow. Instead of writing the second transport equation directly in terms of $\sigma$, many investigators have chosen to write a second equation describing the transport of $\varepsilon$, the turbulence dissipation rate, and then find $\sigma$ indirectly as a function of $K$ and $\varepsilon$. This " $K-\varepsilon$ " form of the two-equation turbulence model is currently used more frequently than the $\mathrm{K}-\sigma$ model and appears to be established as the preferred form. It should be emphasized that, in either model, the transport equations for $\sigma$ and $\varepsilon$ are basically heuristic approximations to more exact equations that are not useful because of the unknown correlations they contain. Therefore the rationale for selecting ore or the other depends more on factors like the ease of determining the free parameters and quality of the resulting predictions rather than on a physically "correct" modeling of the original exact equation. 
With this in mind, the VARR II code has been modified to allow the user to select either the standard $\mathrm{K}-\sigma$ model (as derived by J.H. Stuhmiller) or the $\mathrm{K}-\varepsilon$ model (as defined in the Teach-T Code). The method used was to notice that the transport equations for $K$ are identical in both models (except for the values of the free parameters) once the relationship between $\varepsilon, K$ and $\sigma$ is applied. The next step is to substitute for $\varepsilon$ in the $\varepsilon$-transport equation and to convert it into an equivalent transport equation for $\sigma$. Manipulation of the resulting equation yields a transport equation for $\sigma$ that; with the exception of the free parameter values and one additional turbulent transport term, is identical to the original o-equation used in VARR. It is then a simple matter to change the code so that it uses the new free parameters and the additional transport term to produce a new set of $\mathrm{K}-\sigma$ equations that are mathematically equivalent to the $K-\varepsilon$ model. The operations for this conversion are outlined in Appendix III.A.

These changes have been accomplished, and the new model is currently being tested. Comparative results for an LMFBR outlet plenum cooldown transient (described in section III.2) are summarized for selected points in Table III.1. It is seen. that the two models give turbulence parameter predictions which are similar, but the $K, \varepsilon$ values for both $K$ and $\sigma$ are typically. . larger than those predicted by the $K$, model: Consequently, the $K, \varepsilon$ model tends to predict somewhat more efficient turbulent mixing and heat and momentum transport than the $\mathrm{K}, \sigma$ model. 


$$
\frac{\therefore a r}{4 t}
$$

Sis.

III.2 Buoÿant Effects in Two-Dimensional Flows

(So"ồn" Chang)

Thistêfork has consisted of parallel experimental and a!

theoretica infeforts, concerned with the effects of buoyancy upon turbulence and mixing.

Experimental Effort - The effort to-date has provided a design for an experiment which would examine buoyant effects in a two-dimensional constant-velocity flow in which the densimetric Froude number would be increased monotonically (as in an LMFBR shutdown transient). This experiment would make extensive use of the apparatus developed for transient isothermal flow tests described in section III.1.

The search for an optical method of velocity measurement has been less successful, and attention is being turned to mechanical-thermal methods. The optical methods examined are the dual beam, reference beam, añd single-beam laser doppler anemometers. All of these methods are sensitive to optical nonuniformities in the fluid, which produce a spurious velocity signal. Such non-uniformities are inherent in buoyant flows, and the errors which they would introduce cannot be held to acceptablylow values. Consequently, non-optical methods must be used for these measurements. A survey of available non-optical apparatus is currently being pursued.

Theoretical Effort - An investigation has begun to identify the appropriate changes in the available turbulence models which are necessary to include the effects of buoyancy. Currently the effects of mean-buoyancy are incorporated in the VARR-II vertical 
momentum equation through the body-force term F-Buoyant: $-\beta\left(p-\rho_{0}\right)$. However, the influence of this term upon the turbulence field is currently neglected in both the $(K, \sigma)$ and $(K, \varepsilon)$ turbulence models used in the national LMFBR design effort. In the equation for turbulence kinetic energy this term yields an additional source term in the form: $-g \beta\left\langle w^{\prime} T^{\prime}\right\rangle$, where

$\beta \equiv$ fluid temperature coefficient of volume expansion

$g$ gravitational acceleration, $\mathrm{T}^{r} \equiv$ fluid fluctuating temperature, and $\mathrm{w}^{\prime}$ E fluid fluctuating vertical velocity

In the o-equation the corresponding term which is introduced

$$
\begin{aligned}
\text { is }-\frac{\sigma}{\mathrm{K}} \beta g\left\langle\mathrm{w}^{\prime} \mathrm{T}^{\prime}\right\rangle \text {, where } & \\
\mathrm{K} & \equiv \text { Turbulence kinetic energy, and } \\
\sigma & \equiv \text { Turbulence viscosity }
\end{aligned}
$$

The turbulence effects of buoyancy are of importance to designers in that stable mean-flow buoyancy tends to suppress buoyancy production and mixing, with the reverse being true in the case of unstable buoyancy. The implications of this for LMFBR shutdown transients are that the VARR-II code would currently tend to over-predict the degree of turbulent mixing during the transient, since the core-outflow is characterized by both decreasing momentum and buoyancy. Thus, the stability of the flow and the tendency toward stratification in the outlet plenum would be greater than predicted by the model in its current form. Consequently, more severe thermal shocking of structural components would be expected to occur more easily than would be predicted without the buoyant turbulent correction. 
$\because C$

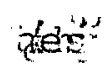

In recent calculations the magnitude of the effects introduced by the terms has been investigated in numerical experiments. The results gigre summarized in Table III.1. The case being calculated is that of an LMFBR outlet Plenum (that of the VARR-II test case, Ref. 2, Transient) in which the inlet velocity is held steady, but the inlet temperature drops from $900^{\circ} \mathrm{F}$ to $700^{\circ} \mathrm{F}$ over a $100 \mathrm{sec}$. interval. Thus, the flow becomes more stable thermally, and as this happens it is expected that the level' of turbulence would decrease, with corresponding decreases in both $\mathrm{K}$ and $\sigma$.

In the transient being stimulated the flow goes from an initial flow isothermal fully-mixed plenum to a thermallystratified flow pattern, with the upper plenum being hot with a recirculating flow in an opposite sense to the cooler recirculating flow in the lower portion of the plenum.

In the test calculations the buoyant turbulent correction accounts for a significant increase in the stability of the stratification, with a strong suppression of turbulence (see the $q$ and $\sigma$ values at selected stations as summarized in Table III.1). Both $q$ and $\sigma$ are suppressed, especially in the inlet zone and thermal interface regions between the stratified hot and cold fluid layers. This is important because these are also the regions in which turbulent mixing is relied upon most in order to avoid flow stratification, and shock to mechanical components. At the end of the inlet cool-down period (at 100 sec into the transient) the outlet nozzle fluid temperature is 
decreased by the corrections from an uncorrected of $832^{\circ} \mathrm{F}$ to a corrected value of $804^{\circ} \mathrm{F}$. This is a change of $14 \%$ of the original fluid temperature decrease at the plenum inlet. The corrected and uncorrected flow patterns at $50 \mathrm{sec}$. into the transient are shown in Figs. III.1 and III.2. It is seen that the buoyant suppression of turbulence has the effect of enlarging the lower recirculation zone, of decreasing transverse momentum transport in the inlet region, and reducing mixing of warm fluid in the upper plenum region with incoming cold fluid. As a result the predicted thermal shock at the outlet nozzle is increased significantly.

An important area to investigate in future work is the proportionality between the eddy diffusivities for heat and momentum. In the previous calculations, just described, the relationships

$$
\begin{aligned}
& \left\langle u^{\prime} v^{\prime}\right\rangle=-\varepsilon_{M} \frac{\partial U}{\partial Z}+\frac{\partial W}{\partial r} \text {, and } \\
& \left\langle w^{\prime} T^{\prime}\right\rangle=-\frac{1}{P r_{t}} \varepsilon_{M} \frac{\partial T}{\partial Z}
\end{aligned}
$$

were used to describe the turbulence correlations. It was assumed that $\mathrm{Pr}_{t}=2$ at all times and places. This treatment can be improved by replacing the constant $\mathrm{Pr}_{t}$ treatment by a calculated value which changes in time and space.

The model for this calculation is a three-equation turbulence model, the turbulence third equation being obtained

2. Clinch River Breeder Reactor Plant Nuclear Island, WARD-D-106, v. 1, 146, Westinghouse Electric Corp. (1975). 


\section{3e}

from the heat conservation equation: ${ }^{3}$. Work in this area during the coming period will focus on investigating the effects of the third turbulence equation in the two models discussed previously. Calculations will $^{\mathrm{w}} 11$ also focus on investigation of the ability of the various models to describe the outlet plenum transient measurements performed in recent years at ANL. $2 \in$

3. C.J. Chen and W. Rodi, A Mathematical Model for Stratified Turbulent Flow and Its Application to Buoyant Jets, 16th IAHR Congress, Sao Paulo (1975).

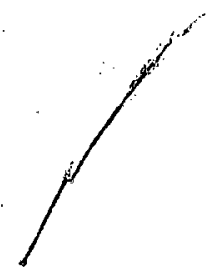


Table III. 1

Results of Negatively-Buoyant LMFBR outlet Plenum Transient Simulations Involving Difference Levels of Buoyant Turbulence Modeling

Time $=100$ Sec Into Transient

\begin{tabular}{|c|c|c|c|c|c|c|c|}
\hline \multirow{2}{*}{ Mode1 } & \multicolumn{2}{|c|}{ Position } & \multirow{2}{*}{$\frac{U}{(f t / s e c)}$} & \multirow{2}{*}{$\frac{W}{(f t / \sec )}$} & \multirow{2}{*}{$\frac{K}{(f t / \sec )^{2}}$} & \multirow{2}{*}{$\frac{\sigma}{\left(f t^{2} / \sec \right)}$} & \multirow{2}{*}{$\frac{\mathrm{T}}{\left({ }^{\circ} \mathrm{F}\right)}$} \\
\hline & $I$ & $\mathrm{~K}$ & & & & & \\
\hline$A$ & 2 & 5 & .134 & 1.18 & .149 & .0161 & 700 \\
\hline $\mathrm{B}$ & & & .333 & 1.18 & .147 & .0155 & 700 \\
\hline $\mathrm{C}$ & & & .262 & 1.18 & .149 & .0167 & 701 \\
\hline A & 2 & 14 & .0524 & .0489 & .0166 & .0714 & 895 \\
\hline $\mathrm{B}$ & & , & .213 & .073 & .0014 & .0014 & 89.9 \\
\hline $\mathrm{C}$ & & & .013 & .051 & .025 & .294 & 895 \\
\hline A & 6 & 4 & .065 & .083 & .0747 & .115 & 828 \\
\hline $\mathrm{B}$ & & & -.069 & .794 & .0007 & .0003 & 802 \\
\hline $\mathrm{C}$ & 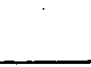 & & .063 & -.675 & .078 & .074 & 808 \\
\hline A & 6 & 7 & .424 & .240 & .060 & .049 & 776 \\
\hline B & & & -.449 & .043 & $E-5$ & $4, \mathrm{E}-6$ & 841 \\
\hline$C$ & & & -.149 & .068 & .097 & .152 & 855 \\
\hline A & 6 & 14 & .076 & .030 & .009 & .057 & 895 \\
\hline$B$ & & & .140 & .167 & $5, E-4$ & $1.5, E-4$ & 897 \\
\hline$c$ & & & .037 & .020 & .023 & .228 & 895 \\
\hline$A$ & 10 & 4 & .276 & .006 & .060 & .096 & 820 \\
\hline $\mathrm{B}$ & & & .143 & -.019 & $E-5$ & $4 ;, \mathrm{G}-6$ & 814 \\
\hline C & & & .163 & .166 & .103 & .229 & 821 \\
\hline
\end{tabular}


Table III.1 (continued)

Model

\begin{tabular}{|c|c|c|c|c|c|c|c|}
\hline Position & I & $\mathrm{K}$ & $\begin{array}{c}U \\
(\mathrm{ft} / \mathrm{sec})\end{array}$ & $\begin{array}{c}W \\
(f t / s e c)\end{array}$ & $\frac{K}{(f t / s e c)^{2}}$ & $\left(f t^{2} / \mathrm{sec}\right)$ & $\begin{array}{l}\mathrm{T} \\
\left({ }^{\circ} \mathrm{F}\right)\end{array}$ \\
\hline A & 10 & $7:$ & -.103 & .103 & .043 & .093 & 838 \\
\hline B & & & -.112 & .043 & $2, E-5$ & $7, E-6$ & 853 \\
\hline$C$ & & & -.053 & .044 & .065 & .209 & 850 \\
\hline A & 10 & 14 & .010 & -.026 & .006 & .049 & 897 \\
\hline$B$ & & & -.027 & -.109 & $3, E-5$ & $1, E-4$ & 896 \\
\hline$c$ & & & .009 & -.018 & .021 & .283 & 895 \\
\hline
\end{tabular}

Madels

$A=k, \sigma$ model with no buoyant turbulence correction

$B=k, \sigma$ model with buoyant turbulence correction in both the $k$ and $\sigma$ equation

$c=k, \varepsilon$ model with no buoyant turbulence-correction 


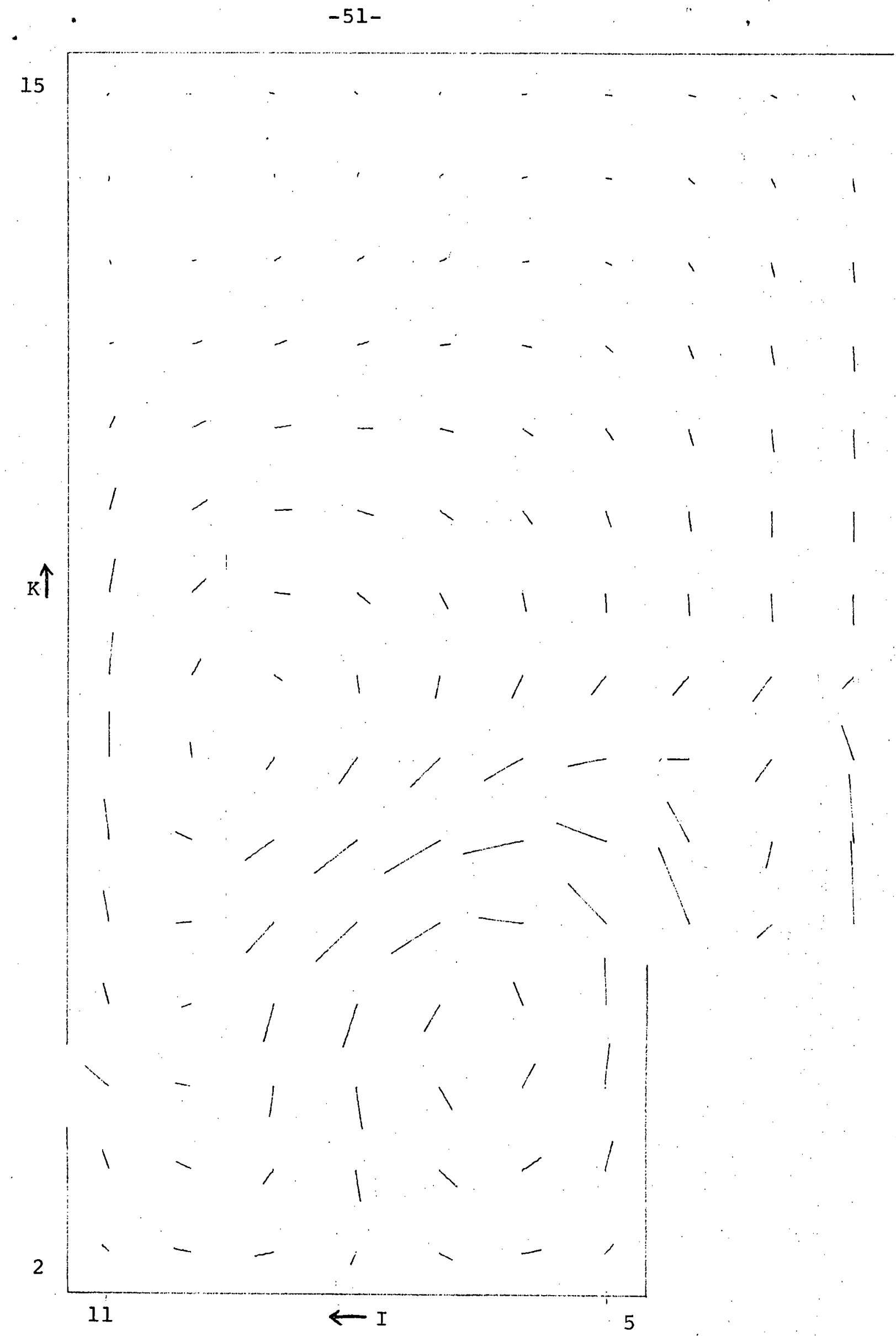

Fig. III.1. Uncorrected LMFBR Cool-Down Transient Calculation Velocity Field, Time $=150 \mathrm{sec}$. 

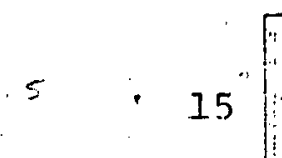

$$
\text { , }
$$<smiles>C1CCCC1</smiles>
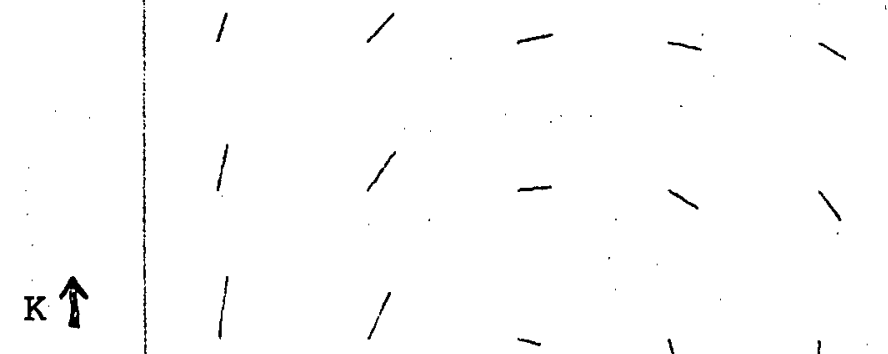

$\mathrm{k} \uparrow$

1

12

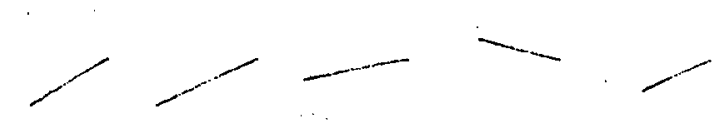

1

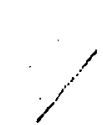<smiles>CCCCC</smiles><smiles>C1CCCCC1</smiles>

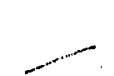

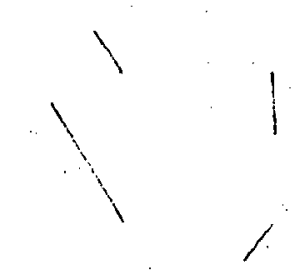

$-\quad-$<smiles>ICI</smiles><smiles></smiles>

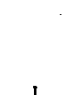

1<smiles>CCCCCCCCCCCCC</smiles>

2

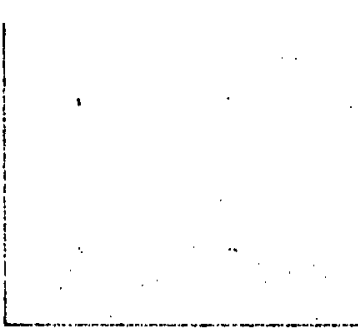

11

$\longleftarrow I$

5

Fig. III.2. Corrected LMFBR Cool-Down Transient Calculations Velocity Field, Time $=150$ sec. 
III.3 Three Dimensional Steady Isothermal Flows

(Robert W. Sawdye)

This effort involves both computational and experimental components, both of which are currently in the initial phases of work.

Computational Effort - Work to date has been directed toward acquiring a library of available three-dimensional flow simulation codes and examining which improvements of their capabilities would be most valuable.

The COMMIX and TEMPEST codes have been developed for three-dimensional flow analysis; however, COMMIX contains a simple turbulence model, and the TEMPEST code presently contains none. One of the tasks of this investigation is to determine the ability of these initial versions to predict turbulent flow fields within a simple three-dimensional geometry. It is anticipated that the codes can be improved by the incorporation of a two-equation turbulence model, such as the $(k, \varepsilon)$ model employed in the TEACH-T code. From the investigation to-date. it is planned to incorporate the $(k, \varepsilon)$ model currently implemented in VARR-II and TEACH-T, with modifications for the treatment of buoyancy (described in section III.2) in TEMPEST when it becomes available. Currently, the status of ANL Turbulence model developments with COMMIX are also being pursued. Experimental Effort - An initial concern is design of an experiment which will test the abilities of simulation codes in calculating inherently three-dimensional flow and turbulence 


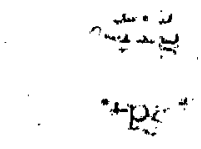

fields. This involves designing both the flow cell and measurement system.

It is currently planned that the test cell will be a rectangular parallelipiped with entrance zones both at a corner and in the center of one face (with only one inlet to be used at a time). The outlets will be on two corners and in the center of the opposite face, in the corners and center of the inlet face, and in the center of one-side face. In any measurement only a single inlet and outlet combination would be used. However, the cell is being designed to be very flexible in the range of flow combinations which can be accommodated. In order to simplify the input conditions for the calculational models, the test section design will attempt to ensure that near-uniform velocities exist at the entrance planes.

The measurement system is designed to permit simultaneous point-measurements of the three dimensional velocity, turbulence, kinetic energy, and Reynolds stress components with a minimum of additional apparatus.

The three velocity components will be measured using two-lasers--one detecting two components in the plane perpendicular to the laser axis with the other laser in that plane measuring the remaining velocity component. The two lasers, optics and photodetectors will be mounted on stationary platforms with the test section translating to allow the measuring point to scan throughout its interior. The electronic processing equipment 
can be modified to allow any two velocity components to be measured simultaneously and correlated, thereby requiring a minimal purchase of equipment. 
IV.

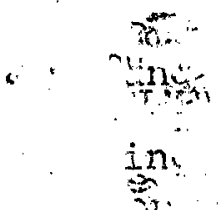

THEOQRETICAL DETERMINATION OF LOCAL TEMPERATURE FIELDS

IN LMFBR FUEL ROD BUNDLES

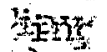

Wire"-Wrapped Rod Bundle Heat Transfer Analysis

(Chuñg-Nin Wong)

During this past quarter, some preliminary calculations mo.

of the simplejeircular duct flow problems using the proposed model $[1,2]$ have been done. The results are not encouraging. Within the medium range of the Reynolds number (i.e., Re > 100), the solution oscillates as the number of iterations increases, and finally it diverges slowly. The cause of this unstable behavior of the solution is due to two factors. One is the cell Reynolds number is greater than two. For steady state problems, if the cell Reynolds number is greater than two, the courant criterion is violated, resulting in instability [3]. The other factor is: Applying the velocities in the adjacent upstream cell as the initial guess is no longer practical if the size of the mesh cell is too large. This initial guess is invalid because it is probably out of the range of the convergence radius of Newton's Method.

Two improvements can be made to solve these problems. The first one is to apply a mesh refinement scheme in order to reduce the mesh size automatically, so that the cell Reynolds number criterion. will be satisfied. The other one is to solve the steady state problem by treating it as a transit problem. However, there is no clear and distinct reason which leads one to believe that this approach will be better or worse. The outcome highly depends upon which time-differencing scheme (i.e, explicit, implicit, or 
semi-implicit) is used and also how long it takes for the transient solution to achieve the equilibrium state. More work is needed and the results will be discussed in the next Progress Report.

1. Chung-Nin Wong, "Coolant Mixing in LMFBR Rod Bundles and Outlet Plenum Mixing Transients - Progress Report, (September' 1978 - November 1978)".

2. Chung-Nin Wong, "Coolant Mixing in LMFBR Rod Bundles and Outlet Plenum Mixing Transients - Progress Report, (December 1978 - February 1979)".

3. P. Roache, "Computational Fluid Dynamics," Hermosa Publishers, 1976. 
ij :é

APTENDIX FOR TASK III

$+\infty$

Outiline of method used to develop a VARR-compatible $\mathrm{K}-\sigma$ turbulence model that is the mathematical equivalent of the $\mathrm{K}-\varepsilon$ turbulence model used in the code TEACH-T.

Definitions: ax.

$$
\mathrm{TKE} \equiv \mathrm{K} \quad \text { Turb. Viscosity } \equiv \sigma
$$$$
\text { TKE Dissipation Rate } \equiv \varepsilon=\frac{\mathrm{C}_{u} \mathrm{~K}^{2}}{\sigma}
$$

Turbulent Kinetic Energy Equation (First equation of twoequation model) . By inspection, the TKE equations used by VARR \& TEACH have the same form:

$$
\frac{\partial K}{\partial t}+U_{j} \frac{\partial K}{\partial X_{j}}=\frac{\sigma}{2}\left(\frac{\partial U_{i}}{\partial X_{j}}+\frac{\partial U_{j}}{\partial X_{i}}\right)^{2}+\frac{\partial}{\partial X_{j}}\left(k_{3} \sigma \frac{\partial K}{\partial X_{j}}\right)-4 k_{7} \frac{K^{2}}{\sigma}
$$

where $k_{3}$ and $k_{7}$ are model constants to be defined later.

Second Equation (Transport equation for $\varepsilon$ in $k-\varepsilon$ model, or transport equation for $\sigma$ in $k-\sigma$ model).

A. $\varepsilon$-transport equation from the TEACH $-\mathrm{T} \mathrm{K}-\varepsilon$ model:

$$
\frac{\partial \varepsilon}{\partial t}+U_{j} \frac{\partial \varepsilon}{\partial X_{j}}=\frac{\partial}{\partial X_{j}}\left(\frac{\sigma}{\sigma_{\varepsilon}} \frac{\partial \varepsilon}{\partial X_{j}}\right)+\frac{C_{1} \sigma \varepsilon}{K}\left(\frac{\partial U_{i}}{\partial X_{j}}+\frac{\partial U_{j}}{\partial X_{i}}\right) \frac{\partial U_{i}}{\partial X_{i j}}-\frac{C_{2} \varepsilon^{2}}{K}
$$

where $\sigma_{\varepsilon} ; C_{1}$, and $C_{2}$ are model constants.

B. $\sigma$-transport equation from the VARR $\mathrm{K}-\sigma$ model: 
$\frac{\partial \sigma}{\partial t}+v_{j} \frac{\partial \sigma}{\partial x_{j}}=\frac{\sigma^{2}}{4 K}\left(\frac{\partial u_{i}}{\partial x_{j}}+\frac{\partial v_{j}}{\partial x_{i}}\right)^{2}+\frac{\sigma}{K} \frac{\partial}{\partial x_{j}} \Gamma \sigma \frac{\partial K}{\partial x_{j}}-\frac{\sigma^{3}}{K^{2}} \frac{\partial}{\partial x_{j}} \Gamma_{1} K \frac{\partial}{\partial} \frac{K}{\partial x_{j}}\left(\frac{K}{\sigma}\right)-4 \alpha_{1} K$

where $\Gamma, \Gamma_{1}, \& \alpha_{1}$ are model constants.

Equations (2) and (3) constitute the $k-\varepsilon$ model, while equations (2) and (4) form the $K-\sigma$ model.

Equation (3) can be coverted into a mathematically equivalent $\sigma$-transport equation by substituting for $\varepsilon$ with Equation ( 1 ).

The result is (after some involved rearrangement):

$$
\frac{\partial \sigma}{\partial t}+u_{j} \frac{\partial \sigma}{\partial x_{j}}=\frac{\sigma^{2}}{K}\left(1=\frac{c_{1}}{2}\right)\left(\frac{\partial_{i}}{\partial x_{j}}+\frac{\partial u_{j}}{\partial x_{i}}\right)^{2}+\frac{2 \sigma}{K} \frac{\partial}{\partial X_{j}}\left(\frac{\sigma}{\sigma_{K}} \frac{\partial K}{\partial x_{j}}\right)
$$

$-\frac{\sigma^{3}}{k^{2}} \frac{\partial}{\partial x_{j}}\left(\frac{2 K}{\sigma_{\varepsilon}}\right) \frac{\partial}{\partial x_{j}}\left(\frac{k}{\sigma}\right)-\frac{1}{\sigma_{\varepsilon}}\left(\frac{\sigma}{K}\right)^{4} \frac{\partial}{\partial x_{j}}\left(\frac{k^{4}}{\sigma^{3}} \frac{\partial \sigma}{\partial x_{j}}\right)-c_{\mu}\left(2-c_{2}\right) K$

NOTE :

With the exception of errors introduced by the finite difference approximations, use of Eqns. (2) \& (5) in a fluid dynamics code should yield the same results as use of Equations (2) and (3), i.e. the $K-\varepsilon$ model results.

Comparison of Eqs. (5) and (4) shows the similarity of the VARR $\sigma$-equation and the TEACH $\varepsilon$-equation. Except for the model 
free parameters, the two equations differ only by the extra. transport termatis) designatedin Eq. (5)

Equation: (5) aan be re-written in terms of generalized constants to charify the conversion between the two model types:

$$
\begin{gathered}
\frac{\partial \sigma}{\partial t}+u_{j} \frac{\partial \sigma}{\partial x_{j}^{4}}=k_{1} \frac{\sigma^{2}}{k}\left(\frac{\partial v_{i}}{\partial x_{j}}+\frac{\partial u_{j}}{x_{i}}\right)^{2}+k_{2} \frac{\sigma}{k} \frac{\partial}{\partial x_{j}}\left(k_{3} \sigma \frac{\partial K}{\partial x_{j}}\right) \\
-\frac{\sigma^{3}}{k^{2}} \frac{\partial}{\partial x_{j}} k_{4} k \frac{\partial}{\partial x_{j}}\left(\frac{k}{\sigma}\right)-\frac{k_{5}}{\sigma_{\varepsilon}}\left(\frac{\sigma}{K}\right)^{4} \frac{\partial}{\partial x_{j}}\left(\frac{k^{4}}{\sigma^{3}} \frac{\partial \sigma}{x_{j}}\right)-4 k_{6}^{k}
\end{gathered}
$$

Equations (1) and (6) form the two models based on selection of the $k_{i}$ values below:

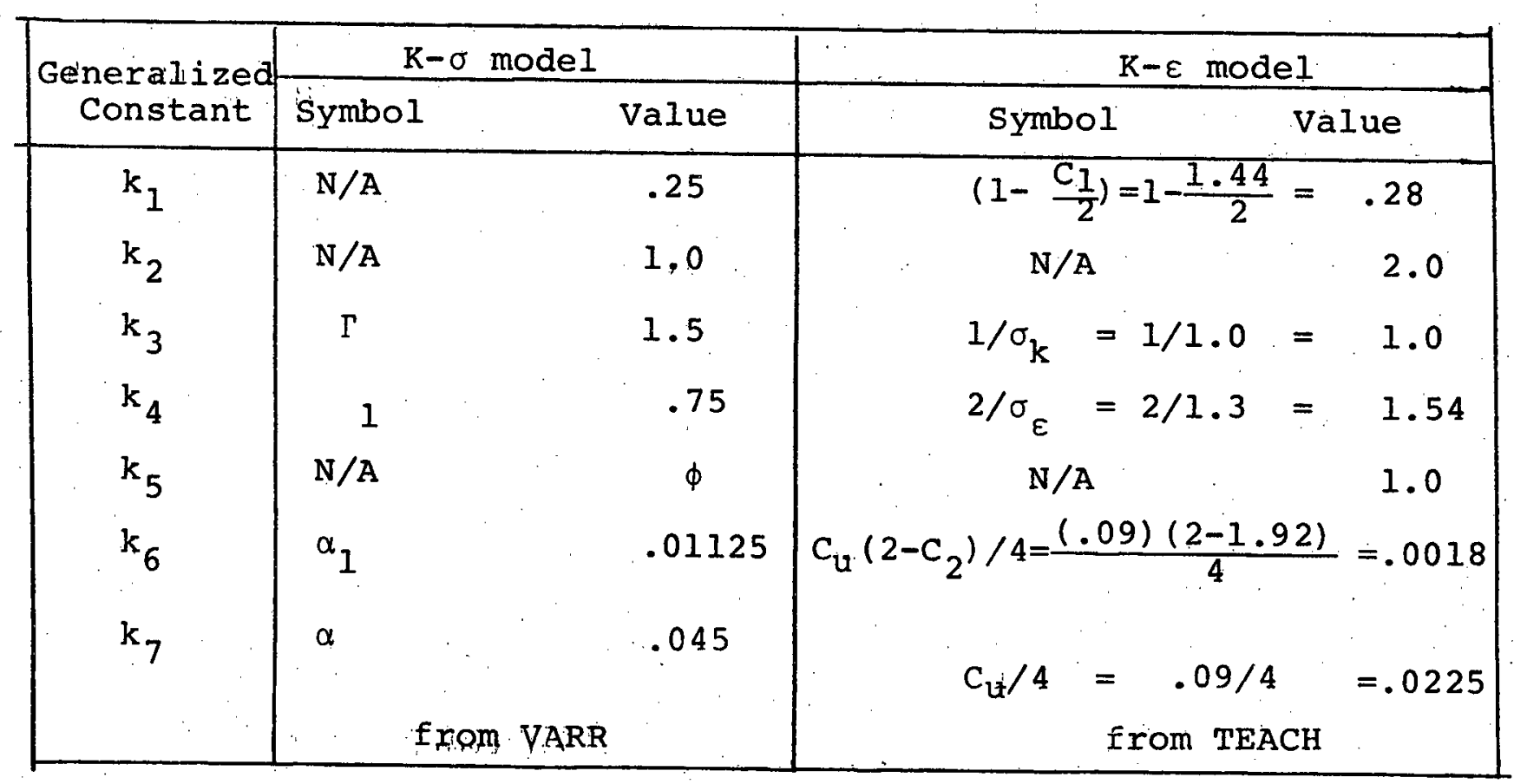

